This item was submitted to Loughborough's Research Repository by the author.

Items in Figshare are protected by copyright, with all rights reserved, unless otherwise indicated.

\title{
Evaluation of the benefits of vehicle safety technology: the MUNDS study
}

PLEASE CITE THE PUBLISHED VERSION

http://dx.doi.org/10.1016/j.aap.2013.02.027

\section{PUBLISHER}

(c) Elsevier Ltd.

\section{VERSION}

AM (Accepted Manuscript)

\section{LICENCE}

CC BY-NC-ND 4.0

\section{REPOSITORY RECORD}

Fildes, Brian, Michael Keall, Pete Thomas, Kalle Parkarri, Lucia Pennisi, and Claes Tingvall. 2019. "Evaluation of the Benefits of Vehicle Safety Technology: The MUNDS Study”. figshare. https://hdl.handle.net/2134/12239. 
This item was submitted to Loughborough's Institutional Repository (https://dspace.lboro.ac.uk/) by the author and is made available under the following Creative Commons Licence conditions.

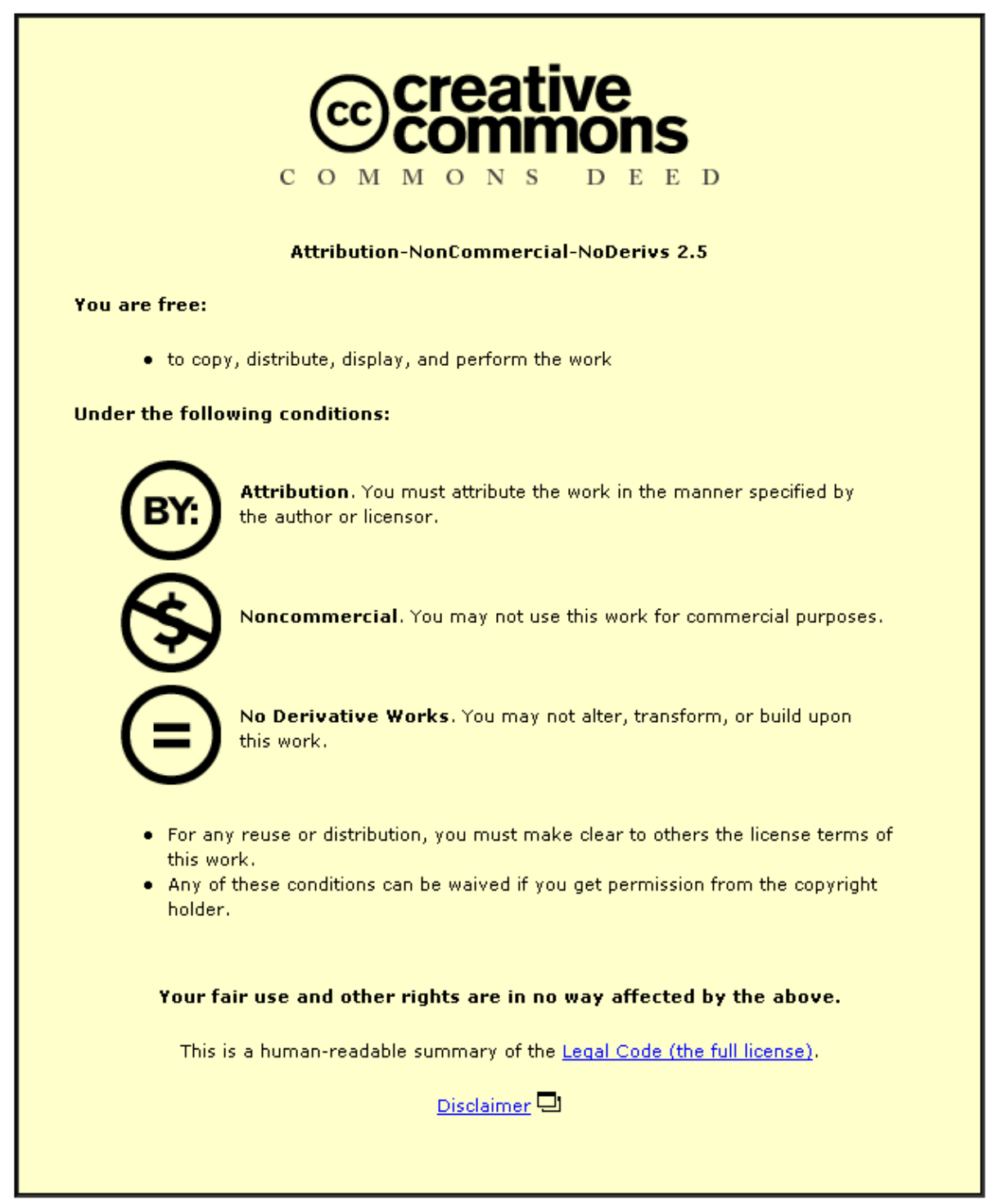

For the full text of this licence, please go to: http://creativecommons.org/licenses/by-nc-nd/2.5/ 
Title: Evaluation of the Benefits of Vehicle Safety Technology: The MUNDS Study

\title{
Authors:
}

Brian Fildes, Monash University Accident Research Centre, Melbourne, Australia

Michael Keall, University of Otago, New Zealand

Pete Thomas, Transport Safety Research Centre, Loughborough University, UK

Kalle Parkkari, Finnish Motor Insurers Centre, VALT

Lucia Pennisi, Automobile Club of Italy, Rome, Italy

Claes Tingvall, Swedish Transport Administration, Borlänge, Sweden

\section{Contact Author:}

Brian N. Fildes, Monash University Accident Research Centre, Melbourne, Australia, Building 70, Monash University, Wellington Road, Clayton, 3800, Victoria, Australia, +61 39905 4369, email: brian.fildes@monash.edu.

\section{Funding sources:}

Swedish Transport Administration, Sweden; and The Australian Government Department of Infrastructure and Transport, Canberra, Australia.

\section{Conflict of Interest:}

This article has not been published in any form and is not under consideration for publication elsewhere. While one of the author's organisations part-funded the research, there was no cohesion by that organisation or influence in terms of the conduct of the research or its findings.

\begin{abstract}
:
Real-world retrospective evaluation of the safety benefits of new integrated safety technologies is hampered by the lack of sufficient data to assess early reliable benefits. This MUNDS study set out to examine if a "prospective" case-control meta-analysis had the potential to provide more rapid and rigorous analyses of vehicle and infrastructure safety improvements. To examine the validity of the approach, an analysis of the effectiveness of ESC using a consistent analytic strategy across 6-European and Australasian databases was undertaken. It was hypothesized that the approach would be valid if the results of the MUNDS analysis were consistent with those published earlier (this would confirm the suitability of the MUNDS approach). The findings confirm the hypothesis and also found stronger and more robust findings across the range of crashtypes, road conditions, vehicle sizes and speed zones than previous. The study recommends that while a number of limitations were identified with the findings that need be addressed in future research, the MUNDS approach nevertheless should be adopted widely for the benefit of all vehicle occupants.
\end{abstract}

\section{Highlights:}

The study proposes a new and valid "prospective" method for conducting case-control meta-analyses of safety technologies to reduce the time taken to confirm their crash effectiveness.

\section{Key Words:}

Safety Technology, Data Analysis, Benefits, Crashes, Innovation 


\subsection{INTRODUCTION}

Advanced safety technologies are increasing rapidly in passenger and commercial vehicles as industry, government and the community currently focus on improved integrated safety systems (Giebel et al, 2008; Sayer et al, 2011). It is claimed that adopting an integrated safety approach has the capability of significantly reducing road trauma (Resendes and Sill, 2012). Unfortunately, there is only limited real-world evidence of their potential to reduce crashes or improved injury outcomes. It is critical to establish their likely crash benefits to help guide manufacturer, government and community judgments about which technologies should be pursued to encourage their widespread introduction and ensure maximum market penetration.

Real-world retrospective evaluation of safety benefits is hampered by the lack of sufficient data to obtain early reliable benefits of new innovative safety systems in vehicles and infrastructure. Individual crash databases are limited by the slow take-up rates of these new technologies as well as lower crash rates by owners of new safer vehicles. It took over 5-years for the benefits of Electronic Stability Control (ESC) braking systems to be initially reported, even in the USA where they have large, comprehensive databases of new vehicle populations and crashed vehicles (e.g., Lie, et al, 2004; Farmer 2004). New systems are commonly available on only a few car models and sometimes optional which increases the time needed to assess their benefits.

One way of potentially speeding up this process is to adopt a wider approach to collecting and analyzing crash data, rather than simply relying on one country's analysis from their limited crash numbers. In order to decrease the reporting time, it should be possible to increase the available relevant crash data by combining data from a number of countries and databases to enable mass-data analyses to be conducted more quickly.

\subsubsection{Meta-Analysis}

The Medical Dictionary (2013) defines meta-analysis as a systematic method of evaluating statistical data based on the results of a number of independent studies of the same problem. They note that meta-analysis can produce a stronger conclusion than that of any individual study. Classic use of meta-analysis is that adopted by the Cochran Collaboration, a project in 10 international centres that combines the findings of various medical randomized control trials of a common theme and publish the findings electronically for distribution to practitioners (Cochran Collaboration (2013).

Meta-analyses traditionally rely on bringing together existing published case-control studies that fit their particular selection criteria. This ensures a degree of consistency across these studies. While the approach has been used in the medical arena for many years, it does rely on retrospectively published studies. Indeed, such an approach has been used recently in evaluating ESC in vehicles by Erke (2008) and Høye (2011).

While retrospective meta-analyses are very useful for helping to assessing vehicle safety improvements, they can only be assembled from evaluations (clinical trials) already published in the scientific literature and thus still subject to long delays. An alternative approach (what we have labelled prospective meta-analyses) would be to initiate a collaborative study involving the assembly of a number of independent aggregate analyses from several countries using a common study design. This brings together a much larger pool of data than any one country has available and speeds-up the process of evaluating safety technologies. Furthermore, it provides a more internationally relevant assessment of the safety benefits than any one single country can provide. 


\subsubsection{The MUNDS Study}

To test this hypothesis, a MUltiple National Database Study (MUNDS), was setup using a case-control, "prospective meta-analysis, approach". The MUNDS approach differed from traditional meta-analyses in that the Chief Investigators actually prescribed what was to be analysed and the controlling factors for each of the participating data providers who independently undertook an analysis of their own database. This was necessary as data from national databases cannot usually be shared for reasons of policy, privacy and confidentially.

Aggregate analyses were undertaken in collaboration with a number of national police databases in Europe and Australasia and provided to the MUNDS team, ensuring a degree of consistent design across each analysis. While Erke (2008) and Høye (2011) for instance have published the results of a "retrospective" meta-analysis of ESC technology as described above, to the authors' knowledge, this is the first application of a "prospective" meta-analysis approach being used for the specific purpose of accelerating an evaluation in evaluating vehicle safety technology.

To test the feasibility of the method, it was decided to select a safety technology that was now well established in terms of its effectiveness. One technology shown to reduce significantly the number of crashes and injuries on the road is Electronic Stability Control or ESC. A number of studies have been undertaken on ESV effectiveness that collectively shows a marked reduction in the number of crashes (see Table 1).

Virtually all methods by which the effects of ESC on crashes have been investigated involve a comparison between the crash involvement of ESC-equipped vehicles and nonESC equipped vehicles (Høye, 2011). Ideally other vehicle and driver characteristics that might affect the risk estimated need to be controlled for. One common way of doing this, in conjunction with the fitment of statistical models with covariates, is to use a comparison group of crashes to represent exposure to risk. Such a comparison group of crashes should be those assumed not to be affected by ESC (or other attributes of ESCequipped vehicles or their drivers), and commonly include rear-end collisions or other crashes not involving loss of control of the focus vehicle. Rear-end crashes, particularly those where the vehicle of interest is struck from the rear, provide quite a good measure of exposure to risk, although there is no perfect set of comparison crashes to provide this measure (Keall and Newstead, 2009).

It is important to ensure that variations across these databases do not influence the final results. Thus, factors such as vehicle and driver age, speed variations, vehicle size, crash types, and road and weather conditions need to be similar. These factors can be adjusted for using regression analyses in developing the statistical model.

\subsubsection{Study Objectives}

The MUNDS study aimed at developing a new approach to evaluating vehicle safety technologies using real-world crash data that allows much shorter lead times for results with many differing databases used and without pooling raw data. The study set out to compare its findings with relevant similar studies as a test of the feasibility of the new approach. The hypothesis to be tested was that the results of the MUNDS analysis are consistent with those published earlier (this would confirm the suitability of the MUNDS approach). In addition, other characteristics of the effectiveness of ESC in terms of crash and environmental features also generally concur. 
Table 1: Summary of Retrospective Studies of ESC Effectiveness (from Scully and Newstead, 2007)

\begin{tabular}{|c|c|c|c|c|}
\hline Author \& Year & Jurisdiction & Crash type & $\begin{array}{l}\text { Exposure } \\
\text { Measure }\end{array}$ & $\begin{array}{l}\text { Crash } \\
\text { reduction }\end{array}$ \\
\hline Becker et al, 2003 & Germany & Skidding accidents & & $45 \%$ \\
\hline Aga \& Okada, 2003 & Japan & $\begin{array}{l}\text { All single vehicle crashes } \\
\text { Severe single vehicle crashes } \\
\text { Head-on crashes } \\
\text { Severe head-on crashes }\end{array}$ & & $\begin{array}{l}35 \% \\
50 \% \\
30 \% \\
40 \%\end{array}$ \\
\hline Lie et al, 2004 & Sweden & $\begin{array}{l}\text { All crashes } \\
\text { All crashes - wet roads } \\
\text { All crashes - snow \& ice }\end{array}$ & $\begin{array}{l}\text { induced } \\
\text { exposure }\end{array}$ & $\begin{array}{l}22.1 \% \\
31.5 \% \\
38.2 \%\end{array}$ \\
\hline Farmer, 2004 & USA & $\begin{array}{l}\text { All single vehicle crashes } \\
\text { Fatal single vehicle crashes }\end{array}$ & $\begin{array}{l}\text { vehicle } \\
\text { registration }\end{array}$ & $\begin{array}{l}41.0 \% \\
56.0 \%\end{array}$ \\
\hline Dang, 2004 & USA & $\begin{array}{l}\text { All single car crashes } \\
\text { All single SUV crashes } \\
\text { Fatal single car crashes } \\
\text { Fatal single SUV crases }\end{array}$ & $\begin{array}{l}\text { induced } \\
\text { exposure }\end{array}$ & $\begin{array}{l}35 \% \\
67 \% \\
30 \% \\
63 \%\end{array}$ \\
\hline Kriess et al, 2005 & Germany & $\begin{array}{l}\text { All ESC sensitive crashes } \\
\text { Fatal ESC sensitive crashes }\end{array}$ & $\begin{array}{l}\text { induced } \\
\text { exposure }\end{array}$ & $\begin{array}{l}32.4 \% \\
55.5 \%\end{array}$ \\
\hline Bahouth, 2005 & USA & $\begin{array}{l}\text { Multi-vehicle crashes } \\
\text { Single-vehicle crashes }\end{array}$ & $\begin{array}{l}\text { induced } \\
\text { exposure }\end{array}$ & $\begin{array}{l}11.2 \% \\
52.6 \%\end{array}$ \\
\hline Page \& Cuny, 2006 & France & All crashes & $\begin{array}{l}\text { induced } \\
\text { exposure }\end{array}$ & $\begin{array}{c}44 \% \\
\text { (not sig) }\end{array}$ \\
\hline $\begin{array}{l}\text { Green \& Woodroofe, } \\
2006\end{array}$ & USA & $\begin{array}{l}\text { Single car crash - dry road } \\
\text { Single SUV crash - dry road } \\
\text { Rollover car crash - dry road } \\
\text { Rollover SUV crash - dry road } \\
\text { Run-off-road car crash } \\
\text { Run-off-road SUV crash }\end{array}$ & $\begin{array}{l}\text { induced } \\
\text { exposure }\end{array}$ & $\begin{array}{l}30.5 \% \\
49.5 \% \\
39.7 \% \\
72.9 \% \\
54.5 \% \\
70.3 \%\end{array}$ \\
\hline Lie et al, 2006 & Sweden & $\begin{array}{l}\text { All injury crashes (no rear-end) } \\
\text { All KSI crashes } \\
\text { Lost control KSI crash - wet } \\
\text { Lost control KSI crash - ice/snow }\end{array}$ & $\begin{array}{l}\text { induced } \\
\text { exposure }\end{array}$ & $\begin{array}{l}16.7 \% \\
21.6 \% \\
56.2 \% \\
49.2 \%\end{array}$ \\
\hline Farmer, 2006 & USA & $\begin{array}{l}\text { All single car crashes } \\
\text { All single SUV crashes } \\
\text { Fatal single car crashes } \\
\text { Fatal single SUV crashes } \\
\text { Multi-vehicle car crashes } \\
\text { Multi-vehicle SUV crashes }\end{array}$ & $\begin{array}{l}\text { vehicle } \\
\text { registration }\end{array}$ & $\begin{array}{c}33 \% \\
49 \% \\
53 \% \\
59 \% \\
25 \% \\
32-37 \%\end{array}$ \\
\hline Scully \& Newstead, 2007 & Australia & $\begin{array}{l}\text { All vehicles (driver injured) } \\
\text { All single car crashes } \\
\text { All single SUV crashes }\end{array}$ & $\begin{array}{l}\text { induced } \\
\text { exposure }\end{array}$ & $\begin{array}{l}32 \% \\
27 \% \\
68 \%\end{array}$ \\
\hline Thomas, 2006 & UK & $\begin{array}{l}\text { All crashes (driver injured) } \\
\text { Wet roads } \\
\text { lcy roads } \\
\text { Small cars }\end{array}$ & $\begin{array}{l}\text { induced } \\
\text { exposure }\end{array}$ & $\begin{array}{l}3 \% \\
34 \% \\
53 \% \\
47 \%\end{array}$ \\
\hline
\end{tabular}

Note: the exposure measure used in these studies can account for differences in the size of the crash reduction and these are included here for interpretation. The induced exposure method is commonly used in these studies today as a useful, consistent measure across studies. 


\subsection{METHOD}

\subsubsection{Data}

Suitable national police data were available from Australia, Finland, Italy, New Zealand, Sweden and the UK for crash-involved light passenger vehicles manufactured in the year 2000 or later (see Table), excluding commercial vehicles (MPVs/vans, utility vehicles/pickup trucks). The fitment of ESC is not routinely coded in national crash data which was a potential challenge. Supplementary records were used by each country to code for ESC fitment which took additional effort by the data providers. Only vehicles that could be definitely coded as having ESC or not were included in the analysis and those where ESC fitment was uncertain were excluded. Different countries also have different thresholds for recording crashes, which can create difficulties in interpreting results when the data are combined. For this study, we chose the highest common threshold to define the scope of crashes studied: crashes in which an injury occurred to any road user involved in the crash. The one exception was Finland, where data only included crashes where the driver was injured.

Table 2: Number of vehicles manufactured from 2000 to 2008 involved in an injury crash that were included in the analysis (excluding those vehicles where ESC fitment was unknown)

\begin{tabular}{lccccccc}
\hline $\begin{array}{l}\text { ESC } \\
\text { fitted? }\end{array}$ & Australia* $^{*}$ & Finland** $^{*}$ & Italy $^{+}$ & $\begin{array}{c}\text { New } \\
\text { Zealand }\end{array}$ & Sweden & UK & Total \\
\hline No & 24,324 & 3,646 & 5,034 & 2,828 & 12,859 & 23,942 & 72,633 \\
Yes & 1,247 & 343 & 14,614 & 194 & 4,880 & 7,172 & 28,450 \\
Total & 25,571 & 3,989 & 19,648 & 3,022 & 17,739 & 31,114 & 101,083 \\
Years & $2001-5$ & $2000-8$ & 2008 & $2001-5$ & $2003-10^{++}$ & $2002-5$ & \\
\hline
\end{tabular}

*only includes the States New South Wales and Victoria

$* *$ only includes vehicles in crashes where the driver was injured

${ }^{+}$only includes vehicles with year of manufacture 2006, 2007 and 2008

${ }^{++}$includes crashes occurring up to and including the end of January 2010

Note that there were differences between countries in terms of the proportions of the fleets identified with ESC. This was partially a function of the data bases in each country, partially a reflection of the fleets that were studied, and partially the restrictions placed on the data provided (for example, the Italian data only had late model vehicles). As the statistical models fitted included year of manufacture as a covariate and the outcome of interest was the ratio of crashes for given vehicle/road/country combinations, such intercountry differences did not adversely affect the estimates derived from the models fitted.

\subsubsection{Combining data sets}

A challenge for any analysis that derives single estimates of safety by combining different countries' crash data is data compatibility. This was examined by first meeting with each data provider to iron out any potential definitional issues. There were potential differences between countries in definitions of crash types, crash severity, speed limit thresholds, and crash conditions (including weather). Secondly, the inclusion criteria for crashes and vehicles needed to be consistent across countries, as did the data fields and specifications of categories. The specification of the data fields and categories are shown in Table 3. Rear-end crashes are those where the vehicle in question was rear-ended by another vehicle and were used as controls in this analysis. 
The model estimates averaged across countries was effectively weighted according to the number of observations (crashed vehicles) in each country. This meant that the data from smaller countries such as New Zealand and Finland, for example, had little influence on the overall estimates. The limitations of this approach are discussed below.

Table 3: Data fields and categories used in international analysis of ESC effectiveness

\begin{tabular}{ccccccccc}
\hline $\begin{array}{c}\text { ESC } \\
\text { fitted? }\end{array}$ & $\begin{array}{c}\text { Year of } \\
\text { M'facture }\end{array}$ & $\begin{array}{c}\text { Vehicle } \\
\text { size }\end{array}$ & $\begin{array}{c}\text { Driver } \\
\text { age }\end{array}$ & $\begin{array}{c}\text { Driver } \\
\text { injury }\end{array}$ & $\begin{array}{c}\text { Crash } \\
\text { Type }\end{array}$ & $\begin{array}{c}\text { Single } \\
\text { Vehicle }\end{array}$ & $\begin{array}{c}\text { Speed } \\
\text { Zone }\end{array}$ & $\begin{array}{c}\text { Road } \\
\text { Cond'n }\end{array}$ \\
\hline Yes/No & year & Large & $<25$ & Fatal & Head-on & Yes $/$ no & $<75 \mathrm{~km} / \mathrm{h}$ & Dry \\
& & small & $25-29$ & Serious & Rollover & & $>75 \mathrm{~km} / \mathrm{h}$ & Wey \\
& & SUV & $30-39$ & Minor & Rear-end & & & Snow \\
& & & $40-49$ & None & other & & & Ice \\
& & & $50-59$ & & & & & \\
\hline
\end{tabular}

Given that those who own or manage crash databases were either unwilling or not able legally to provide individual case records to a single research facility, the MUNDS team structured a series of blank summary tables which were sent to each data provider for completion (see Table 3). The tables of data were structured to provide the relevant data for the multivariate analysis. Completed tables and associated details were forwarded to the MUNDS statistician who then combined them as input for a series of overall analyses, as described in the next subsection.

\subsubsection{Analysis}

Once the data from the various countries were compiled in compatible forms, they were pooled so that statistical models could be fitted. Using a logistic regression technique, statistical models were fitted to the data to ensure that the estimates were adjusted for important factors that could confound estimates of ESC effectiveness. These included: vehicle ages, types and sizes; road conditions; driver age. Quasi-induced exposure methods (Keall and Newstead, 2009) were used to estimate the risk of crashes of particular types, where counts of rear-end crashes represented exposure to risk. Logistic models were fitted to an outcome variable $Y$ set as follows:

$$
\begin{aligned}
& Y=1 \text { (crashes excluding rear-ends) } \\
& Y=0 \text { (rear-end crashes) }
\end{aligned}
$$

The odds of a non-rear-end crash using this data set are equivalent to the risk of nonrear-end crash involvement if the counts of rear-end crashes are considered to act as a measure of exposure to risk (ibid). These risk estimates could then be derived directly from the estimated coefficients generated by fitting the logistic models.

Explanatory variables included: ESC (fitted or not fitted); Country; Year of Manufacture; Vehicle Type; Driver Age Category; Speed Zone; Road Condition; and any significant interactions between any two of these factors. The interaction terms and other covariates served to control for potentially confounding effects that could otherwise bias the estimates of ESC effectiveness, except in cases where variables interacted in a statistically significant manner with ESC fitment (which are shown as column headings in the following tables). The "forwards selection" approach was used to fit the models, adding one variable at a time to the model until a point was reached 
where no remaining variable made a significant partial contribution to predicting the odds of a non-rear-end crash.

All final models fitted well, with Hosmer-Lemeshow goodness-of-fit statistics (Hosmer and Lemeshow, 2000) that were not significant. There was some modest overdispersion, symptomatic of some degree of clustering of the observations or heterogeneity within classes. This was allowed for by estimating an over-dispersion factor by using quasi-likelihood estimation in the model fitting.

\subsection{RESULTS}

The models fitted to the data aggregated across countries provided estimates of relative risk using the prospective meta-analysis approach.

\subsubsection{Single-Vehicle Crashes across Countries}

The results of relative risk of single vehicle crashes by country, road conditions, and speed limit with ESC are shown in Table 4. Relative risk was defined as that involving at least one injury for vehicles with ESC compared to vehicles without ESC, controlling for vehicle size, vehicle year of manufacture, and driver age group. The variables country, road conditions and speed limit were the only variables that had a statistically significant interaction with the ESC variable in the model, indicating that ESC effectiveness varied significantly across these aspects, but not across other variables once these interactions had been included. Results were analysed using odds-ratios and expressed as percent reductions with $95^{\text {th }}$ percentile ranges.

Table 4: By country, road conditions, and speed limit area: reduction in risk of single vehicle crashes that involved at least one injury for vehicles with ESC compared to vehicles without

ESC, controlling for vehicle size, vehicle year of manufacture, driver age group

\begin{tabular}{|c|c|c|c|c|}
\hline & \multicolumn{4}{|c|}{ Road conditions } \\
\hline & Wet/Snow/Ice & Wet/Snow/Ice & Dry & Dry \\
\hline Country & $<75 \mathrm{KMH}$ & $\geq 75 \mathrm{KMH}$ & $<75 \mathrm{KMH}$ & $\geq 75 \mathrm{KMH}$ \\
\hline Australia & $0.88(0.63,1.24)$ & $0.57(0.40,0.80)$ & $1.08(0.79,1.48)$ & $0.69(0.49,0.97)$ \\
\hline Finland* & $0.98(0.64,1.49)$ & $0.62(0.41,0.95)$ & $1.19(0.79,1.80)$ & $0.76(0.51,1.15)$ \\
\hline Italy & $0.62(0.51,0.75)$ & $0.39(0.32,0.49)$ & $0.75(0.65,0.87)$ & $0.48(0.40,0.58)$ \\
\hline New Zealand & $0.78(0.37,1.61)$ & $0.50(0.24,1.03)$ & $0.95(0.46,1.96)$ & $0.61(0.29,1.26)$ \\
\hline Sweden & $0.51(0.42,0.62)$ & $0.33(0.27,0.40)$ & $0.63(0.52,0.74)$ & $0.40(0.33,0.49)$ \\
\hline UK & $0.93(0.76,1.14)$ & $0.60(0.50,0.72)$ & $1.14(0.94,1.38)$ & $0.73(0.61,0.87)$ \\
\hline Average $(95 \% \mathrm{Cl})$ & $0.66(0.57,0.77)$ & $0.46(0.40,0.54)$ & $0.79(0.71,0.89)$ & $0.56(0.49,0.64)$ \\
\hline
\end{tabular}

*Figures in BOLD were those found to be statistically significant (95\% confidence)

The findings in Table 4 show some variability in the estimates of effectiveness between countries; with greatest effectiveness estimated from the Swedish data and least from the Finnish data. It should be noted, however, that there were large sampling errors, particularly for Finland, which were associated with relatively small sample sizes. This confirms the difficulty of finding robust results from a single country as well as crash differences between countries. In conditions where vehicles are most liable to lose control (wet/snow/ice), the estimates in Table 4 revealed greatest effectiveness for ESC, as expected. Similarly, ESC was found to be most effective in higher speed limit areas, related to the greater difficulty of maintaining control of vehicles at higher speeds. 


\subsubsection{Single-Vehicle Crashes by Road, Speed and Vehicle Type}

In conditions where vehicles are most liable to lose control (wet/snow/ice), the estimates revealed greatest effectiveness for ESC as expected (Table 5). Similarly, ESC was found to be most effective in higher speed limit areas, probably related to greater difficulties by the driver in maintaining control of vehicles at high speed. Logically, the highest degree of effectiveness was estimated for higher speed limit roads when the roads are affected by rain/snow/ice (overall relative risk of 0.46 , with $95 \%$ CI 0.40 to 0.54 ).

Table 5: By vehicle type, speed zone, and road conditions

\begin{tabular}{lccc}
\hline Vehicle & Speed zone & Road conditions & Reductions \\
\hline Small car & $<75 \mathrm{~km} / \mathrm{h}$ & Wet/Snow/Ice & $0.69(0.59,0.82)$ \\
Small car & $<75 \mathrm{~km} / \mathrm{h}$ & Dry & $0.83(0.73,0.94)$ \\
Small car & $\geq 75 \mathrm{~km} / \mathrm{h}+$ & Wet $/$ Snow $/$ Ice & $0.49(0.41,0.59)$ \\
Small car & $\geq 75 \mathrm{~km} / \mathrm{h}+$ & Dry & $0.59(0.51,0.69)$ \\
\hline Large car & $<75 \mathrm{~km} / \mathrm{h}$ & Wet $/$ Snow $/$ Ice & $0.63(0.52,0.76)$ \\
Large car & $<75 \mathrm{~km} / \mathrm{h}$ & Dry & $0.75(0.64,0.89)$ \\
Large car & $\geq 75 \mathrm{~km} / \mathrm{h}+$ & Wet $/$ Snow $/$ Ice & $0.45(0.37,0.54)$ \\
Large car & $\geq 75 \mathrm{~km} / \mathrm{h}+$ & Dry & $0.54(0.45,0.64)$ \\
\hline SUV & $<75 \mathrm{~km} / \mathrm{h}$ & Wet $/$ Snow $/ \mathrm{Ice}$ & $0.48(0.33,0.72)$ \\
SUV & $<75 \mathrm{~km} / \mathrm{h}$ & Dry & $0.58(0.40,0.84)$ \\
sUV & $\geq 75 \mathrm{~km} / \mathrm{h}+$ & Wet $/$ Snow $/ \mathrm{Ice}$ & $0.34(0.23,0.51)$ \\
SUV & $\geq 75 \mathrm{~km} / \mathrm{h}+$ & Dry & $0.41(0.28,0.60)$ \\
\hline
\end{tabular}

Despite the lack of significance for the interaction between ESC fitment and vehicle size and type in this analysis, when this interaction was forced into the model, the resultant estimates enabled comparisons to be made between the current study and previous studies that included vehicle type. The largest difference was found for SUVs compared to cars (whether large or small) with a highly significant $66 \%$ reduction in crash risk for SUVs in higher speed limit roads in wet/snowy/icy road conditions.

Previous analyses of the effectiveness of ESC have found a differential effect by vehicle type, in particular greater effectiveness for SUVs in single vehicle crashes. The present analysis found that the variables speed limit area and weather conditions, together, were stronger variables in explaining the effectiveness of ESC than vehicle type, and variable type became statistically insignificant when the analysis was adjusted for speed limit and weather conditions.

\subsubsection{Multi-Vehicle Crashes}

Statistical models were fitted to crashes involving multiple vehicles. Again, the reduction in risk of multi-vehicle crashes for vehicles with ESC compared to vehicles without ESC was estimated, controlling for vehicle size, vehicle year of manufacture, driver age group, as before. However, these models generally revealed smaller safety benefits for ESC in these crashes, which again is consistent with earlier analyses.

In this analysis, there was a $7 \%$ improvement on lower speed limit roads and $14 \%$ in higher speed zones. The average of these was a statistically significant 9\% (95\% CI 4\%$13 \%$ ) reduction in risk when weighted by crash numbers across the speed zones. However, as shown in Table 6, there was a significant interaction between speed zone with fitment of ESC in explaining crash risk. 
Table 6: Reduction in risk of multi-vehicle injury crashes by country and speed limit area (statistically significant changes are bolded; negative values are estimated increases)

\begin{tabular}{lcc}
\hline & \multicolumn{2}{c}{ Speed limit of crash site } \\
Country & $<75 \mathrm{KMH}$ & $\geq 75 \mathrm{KMH}$ \\
\hline Australia & $1.07(0.91,1.24)$ & $0.94(0.79,1.12)$ \\
Finland* & $1.14(0.75,1.72)$ & $1.00(0.65,1.53)$ \\
Italy & $0.91(0.82,1.01)$ & $\mathbf{0 . 8 0}(0.70,0.91)$ \\
New Zealand & $1.11(0.72,1.70)$ & $0.97(0.63,1.50)$ \\
Sweden & $\mathbf{0 . 8 0}(0.73, \mathbf{0 . 8 8})$ & $\mathbf{0 . 7 1}(0.62,0.81)$ \\
UK & $1.03(0.95,1.13)$ & $\mathbf{0 . 9 1}(\mathbf{0 . 8 3}, \mathbf{1 . 0 0})$ \\
\hline Average (95\%Cl) & $\mathbf{0 . 9 3 ( 0 . 8 8 , 0 . 9 9 )}$ & $\mathbf{0 . 8 6}(\mathbf{0 . 7 9}, \mathbf{0 . 9 4})$ \\
\hline
\end{tabular}

*Finland data consists solely of crashes where the driver was injured

\subsubsection{Comparative Findings}

A comparison of the overall findings from the MUNDS study with previous reported effectiveness studies is shown in Table 7. The degree of consistency is generally very high for all crashes (13\% c.f $16.7 \%$ and $22.1 \%$ by Lie et al, 2004 and 2006) although less than the figures of $45 \%$ reported by Becker et al (2003) in Germany and $44 \%$ (not significant) by Page and Cuny (2006) in France. Moreover, the findings of $35 \%$ for MUNDS effectiveness in single vehicle car crashes $52 \%$ for SUVs compared well with the range of earlier findings from $30.5 \%$ to $52.6 \%$ for cars and $49 \%$ to $68 \%$ for SUVs across the various Japanese, US and Australian figures. In addition, the MUNDS $9 \%$ reduction in multi-vehicle car crashes was reasonably consistent with similar reports by Bahouth (2005) and Farmer (2006) from Germany and the US.

Table 7: Comparison between MUNDS study of ESC and other studies

\begin{tabular}{|c|c|c|c|c|}
\hline Author \& Year & Jurisdiction & Crash type & $\begin{array}{l}\text { Crash } \\
\text { reduction }\end{array}$ & $\begin{array}{l}\text { MUNDS } \\
\text { estimates }\end{array}$ \\
\hline Becker et al, 2003 & Germany & Skidding accidents & $45 \%$ & $13 \%(9 \%-17 \%)$ \\
\hline Aga \& Okada, 2003 & Japan & All single vehicle crashes & $35 \%$ & $35 \%(29 \%-40 \%)$ \\
\hline Lie et al, 2004 & Sweden & $\begin{array}{l}\text { All crashes } \\
\text { All crashes - wet roads } \\
\text { All crashes - snow \& ice }\end{array}$ & $\begin{array}{l}22.1 \% \\
31.5 \% \\
38.2 \%\end{array}$ & $\begin{array}{l}13 \%(9 \%-17 \%) \\
15 \%(8 \%-21 \%)^{*}\end{array}$ \\
\hline Farmer, 2004 & USA & All single vehicle crashes & $41.0 \%$ & $35 \%(29 \%-40 \%)$ \\
\hline Dang, 2004 & USA & $\begin{array}{l}\text { All single car crashes } \\
\text { All single SUV crashes }\end{array}$ & $\begin{array}{l}35 \% \\
67 \%\end{array}$ & $\begin{array}{l}35 \%(29 \%-40 \%) \\
52 \%(30 \%-67 \%)\end{array}$ \\
\hline Bahouth, 2005 & USA & $\begin{array}{l}\text { Multi-vehicle crashes } \\
\text { Single-vehicle crashes }\end{array}$ & $\begin{array}{l}11.2 \% \\
52.6 \%\end{array}$ & $\begin{array}{c}9 \%(4 \%-13 \%) \\
35 \%(29 \%-40 \%)\end{array}$ \\
\hline Page \& Cuny, 2006 & France & All crashes & $44 \%$ (not sig) & $13 \%(9 \%-17 \%)$ \\
\hline $\begin{array}{l}\text { Green \& } \\
\text { Woodroofe, } 2006\end{array}$ & USA & $\begin{array}{l}\text { Single car crash - dry road } \\
\text { Single SUV crash - dry road }\end{array}$ & $\begin{array}{l}30.5 \% \\
49.5 \%\end{array}$ & $\begin{array}{l}30 \%(22 \%-36 \%) \\
49 \%(26 \%-65 \%)\end{array}$ \\
\hline Lie et al, 2006 & Sweden & All injury crashes (no rear-end) & $16.7 \%$ & $13 \%(9 \%-17 \%)$ \\
\hline Farmer, 2006 & USA & $\begin{array}{l}\text { All single car crashes } \\
\text { All single SUV crashes } \\
\text { Multi-vehicle car crashes } \\
\text { Multi-vehicle SUV crashes }\end{array}$ & $\begin{array}{c}33 \% \\
49 \% \\
5 \% \\
32-37 \%\end{array}$ & $\begin{array}{c}35 \%(29 \%-40 \%) \\
52 \%(30 \%-67 \%) \\
9 \%(5 \%-13 \%) \\
6 \%(-17 \%-25 \%)\end{array}$ \\
\hline
\end{tabular}




\begin{tabular}{|l|l|l|c|c|}
\hline $\begin{array}{l}\text { Scully \& Newstead, } \\
2007\end{array}$ & Australia & All single car crashes & $27 \%$ & $35 \%(29 \%-40 \%)$ \\
& & All single SUV crashes & $68 \%$ & $52 \%(30 \%-67 \%)$ \\
\hline Thomas, 2006 & UK & Wet roads all crashes? & $34 \%$ & $15 \%(8 \%-21 \%)^{*}$ \\
& & Icy roads all crashes? & $53 \%$ & $\mathrm{n} / \mathrm{a}$ \\
& & Small cars all crashes? & $47 \%$ & $10 \%(4 \%-15 \%)$ \\
\hline
\end{tabular}

*the MUNDs estimates combine wet, snow and ice

\subsection{DISCUSSION}

The MUNDS study set to compare its findings with relevant similar studies as a test of the validity of the new MUNDS prospective meta-analysis approach. The hypothesis tested was that the results of the MUNDS analysis are consistent with those published earlier. This was intended to confirm the feasibility of the MUNDS approach to elicit faster and more accurate estimates of real-world effectiveness than currently possible. Table 7 shows some results from previous studies with the comparative MUNDS study estimate in the final column. Although the best-fitting final model estimates from the MUNDS data have already been shown in Tables 4 and 5, models were refitted to generate the estimates in Table 7 by averaging across levels of disaggregation. For example, the estimate for all single vehicle crashes was produced by removing the interaction terms of ESC fitment with road conditions, speed limit and country from the model.

Because of the large amount of data accumulated, the estimates from the MUNDS study were produced from statistical models in which many potentially confounding variables were controlled for. Although comparisons between studies are difficult to make when the methods are different (e.g., the types of comparison crashes used), the MUNDS estimates turned out to be very close to the results of many of the earlier studies, particularly the Japanese, Australian and several of the American reports. While it might be said justifiably that this is not a rigorous test of the hypothesis, MUNDS was a separate analysis of the effectiveness using different data to the ones used for comparison and therefore it is an independent validation.

The benefits of the MUNDS approach can be seen in the often quite narrow confidence intervals, which enable relatively small safety benefits to be statistically significantly above zero. In the early days of evaluation of new technology, or when a single jurisdiction is studied, the statistical power to detect even quite substantial safety benefits is very limited (e.g., the $45 \%$ injury reduction that was not statistically significant in Page and Cuny, 2006).

\subsubsection{Characteristics of ESC Crashes}

An additional aspect of this study was to examine the relationships between ESC and other characteristics of the effectiveness of ESC (single-multiple vehicle crashes, road condition, speed limit, and vehicle type). Again, it was expected that these findings would be consistent with earlier findings as further indication of the validity of the MUNDS approach.

\subsubsection{Single- and Multi-Vehicle Crashes}

Previous studies have confirmed that the most obvious benefits of ESC relate to crashes of single-vehicles that lose control. Overall effectiveness benefits range from $30 \%$ to $40 \%$ reduction in crashes for passenger cars, to $49 \%$ up to $68 \%$ for Sport Utility Vehicles (SUVs). These values vary depending on the level of severity of the injury outcome, the road surface, and the study date and region. 
In the MUNDS study, single-vehicle crash reductions among passenger cars varied from ( $30 \%$ to $55 \%$ ) and SUVs ( $42 \%$ to $66 \%$ ), again dependent on the speed zone of the crash, the road condition (dry or wet) and the size of the vehicle. In particular, larger cars had around a $5 \%$ additional benefit from ESC than did small cars, presumably because of the added benefit of vehicle mass as an injury mitigation measure. To our knowledge, no such finding has been previously reported. As in previous studies, the benefits of ESC in single-vehicle crashes are much greater in the wet and at higher crash speeds (higher speed zones).

Crash reductions for vehicle-to-vehicle collisions have been less impressive generally. In this study there was an $\mathrm{X} \%$ reduction over all in multi-vehicle crashes which was not significant in itself, only when merged with speed zone ( $7 \%$ in low speed and $14 \%$ in high speed zones). It is likely that this is an artifact of the modeling process as rear-end crashes have been used in computing induced exposure, assuming they would not benefit from the technology (Dang 2004; Green \& Woodroofe, 2006; Scully and Newstead 2007). In the study by Bahouth (2005), he reported an $11.8 \%$ significant reduction in multi-vehicle frontal crashes using a similar induced exposure method to that used in this study. Dang (2006) reported a $19 \%$ crash reduction for multi-vehicle crashes which was not significant. Scully and Newstead also found a $14.2 \%$ significant reduction in multi-vehicle crashes using an induced exposure method. Both these study findings are consistent with the non-significant trend observed here.

Interestingly, in the study by Farmer (2010), he reported an even larger reduction for ESC of $20 \%$ overall in multi-vehicle crashes (a non-significant $16 \%$ for cars and $21 \%$ for SUVs). Farmer, however, used a different measure of exposure, namely per registered vehicle, to overcome the assumption that rear-end crashes are not influenced by ESC. While this did not appear to impact on the single-vehicle reductions, his findings might be a more realistic assessment of the benefit of ESC in all collisions.

\subsubsection{Road Condition}

The findings for road condition showed that in the conditions where vehicles are most likely to lose control (wet, snow and ice), the findings of the effectiveness of ESC for single vehicle crashes was significantly greater in the wet than on dry roads. Moreover, these findings were greater for crashes at lower speed limits than at higher ones $(62 \%$ at low and $23 \%$ high).

In the study by Lie et al (2004), they reported a $43 \%$ improvement for ESC for wet roads and a $73 \%$ improvement for snow and icy roads, for all crashes of all speeds and all injury severities. In a later report, they claimed the benefits were $29 \%$ great for fatal and serious injury crashes with a substantial $100 \%$ plus added benefit among KSI crashes for wet, snow and icy roads. Farmer (2010) also found substantial benefits for ESC crashes on wet roads in the US comprising $55 \%$ to $63 \%$ for cars and SUVs in single vehicle crashes, and $73 \%$ to $38 \%$ for multi-vehicle collisions.

While these proportions are different across the three sets of data, not expected given the differences in crash types and injury severity, the trends are nevertheless consistent across these studies, confirming the ability of the MUNDS approach to simulate similar responses to those previously published.

\subsubsection{Speed Zone}

It has been claimed that the effects of ESC are likely to be greater at higher speeds where vehicle dynamics performance plays a greater part in the crash (Aga and Okada, 2003). Yet, very few of the previous studies attempted to examine the effects of ESC by 
the speed of the collision, given that national data does not include estimates of the collision speed. Newstead et al, (2010) used the speed limit in which a vehicle crashed as a proxy for low and high speed estimates of the crashes. As each of the databases used in the MUNDS study contained the speed zone in which the crash occurred, it was included as a factor in the meta-analysis.

The results here showed that the influence of ESC was up to twice as effective in preventing crashes in high speed zones as in low speed zones. These effects were consistent for dry and wet roads and for different vehicle types. Interestingly, too, the effects were also consistent for low and high speed zone single-vehicle and multi-vehicle crashes. While we were unable to compare these findings with other ESC effectiveness studies, nevertheless, they were consistent with claims made by Sferco et al (2001), Aga and Okada (2003), and Dang (2004) that inappropriate or excessive speed is frequently identified as a causation factor in both loss of control and other accidents.

\subsubsection{Vehicle Make and Model}

In the MUNDS analysis, ESC had a differential effect depending on vehicle size and type and speed zone. In all cases, the benefits were greater for SUVs over large and small passenger cars, and for large over small cars. The differences were consistent across the different road conditions and speed zones.

Previous studies on the effects of vehicle size are again consistent with these findings. Dang (2004), Green and Woodroofe (2006), Farmer (2006) and Scully and Newstead (2007) all reported significantly larger findings for SUVs over passenger cars. While the apparent slightly higher benefit for large over small cars shown earlier was not statistically significant as a main effect, the finding is consistent with these earlier results.

\subsubsection{The MUNDS Approach}

As noted earlier, this study set out to test the hypothesis that the results of the MUNDS effectiveness analysis (for Electronic Stability Control - ESC) would be consistent with those published earlier. We maintain that the results clearly confirm the validity of the MUNDS approach for estimating technology effectiveness. The findings for the various crash types, road conditions, vehicle size and, to a lesser extent, speed zones, were consistent with earlier findings. In addition, using a meta-analysis approach with strong control over the design of the various individual data analyses, resulted in significant findings, derived from a large sample, with smaller estimation errors.

The MUNDS analysis process aims to allow more rapid accurate assessment of the benefits of the effectiveness of new safety technologies. By pooling the data across four equally-sized jurisdictions, the confidence intervals for the relative risk estimates are approximately halved, meaning that the elapsed time between the introduction of a new technology and the establishment of benefits can also be halved. Of course, quicker evaluation has the potential to prevent mortality and morbidity by promoting safe technologies - if they are indeed effective - or preventing investment in technologies with minimal safety benefits to offer. Further, using a much larger real-world database, the findings are superior in terms of scope of conditions, the numbers of observations, and the tight control exerted over the design and conduct of the various studies included. Many of the earlier studies varied considerably in terms of the study designs, control factors, variations in the data used, exposure processes adopted and various potential confounding factors. 
In studies by Erke (2008) and Høye (2011), the authors conducted a meta-analysis of ESC using existing studies where it was not possible to exert the same level of statistical control as was possible in the MUNDS study, and hence were subject to potential larger variance heterogeneity. Indeed, Erke (2008) noted large heterogeneity in their meta-analysis of existing studies. The MUNDS approach provides a unique rigorous design and ability to conduct these studies without having to wait until sufficient single studies have been published to before undertaking these analyses.

\subsubsection{Limitations}

We acknowledge however that the MUNDS study analysis was not without its limitations.

First, there were likely to be inconsistencies between the databases used in this study. While each contributor used national data, there are differences in the way and accuracy of data collection across the regions. In particular, the way each study assessed injury severity was likely to be different across databases. The Finnish database, for example, only included crashes that resulted in injuries to the driver, which is a source of some heterogeneity, but if we exclude the Finnish data in the analysis, the estimates are unaffected because of the small Finnish sample size. This of course is also a problem for "retrospective" analyses from different studies that also use different databases.

As the vehicle fleets differed across countries, the findings presented here might not be representative of any particular fleet of vehicles. As most of the jurisdictions contributing data were European, the results are probably more representative of Europe as a whole than a series of studies from individual countries. A European-wide or international analysis of effectiveness can potentially make a stronger case for the need for widespread international fitment.

The use of speed zone as a proxy for crash severity is not without some criticism. It implicitly assumes that higher speed zones are associated with higher speed crashes, and lower speed zones with lower speed crashes. Newstead et al (2010) have used this technique in assessing real-world vehicle crashworthiness with some success. Although such assumptions may not affect analyses of large datasets as were available here, it would be useful if this assumption was able to be tested in future research.

The set of comparison crashes used to provide a measure of exposure to risk has been identified by previous research as one of the better induced exposure measures, although driver age and vehicle type are two factors across which the rear-end crashes provide biased measures of exposure (Keall and Newstead, 2009). However, by including these factors as covariates in our models, we have accounted for at least these sources of bias in forming our estimates.

\subsection{CONCLUSION}

As noted earlier, this study set out to test the hypothesis that the results of the MUNDS effectiveness analysis (for Electronic Stability Control - ESC) would be consistent with those published earlier. We contend that the results clearly confirm the validity of the MUNDS approach to estimating technology effectiveness. The values obtained for the effectiveness of ESC in single-vehicle crashes are within the range of values previous reported by several single evaluation studies using differing methodologies and exposure measures. The multi-vehicle findings, too, albeit of less significance, are also in general accord with other studies that used induced exposure metrics. In addition, the percentage reductions reported for the independent variables of road condition and vehicle size and type are further consistent with previous published findings. 
The new methodology developed here using a prospective meta-analysis approach has the advantage of expediting the process of evaluating new vehicle safety technologies. In reality, it is the only feasible method to study real-world safety benefits when one data source is not sufficient. Drawing from a larger pool of crash data enhances the likelihood of demonstrating statistical significance with tighter confidence bounds. The MUNDS approach will be of potential benefit to vehicle manufacturers and suppliers, governments and consumer groups and advocates in prioritising future road safety improvements in active safety. While a number of limitations were identified with the findings that should be addressed in future research, nevertheless, the MUNDS approach needs to be adopted widely for the benefit of all road users.

\section{ACKNOWLEDGEMENTS}

The authors thank the project sponsors, the Swedish Transport Administration in Sweden and The Australian Government Department of Infrastructure and Transport in Australia for their support for this project. In addition, the support of the MUNDS Committee is also gratefully appreciated. Beyond those listed as authors) these people include Manuel Aviles, Spanish Ministry of Transport; Joerg Bakker, Daimler AG; Ola Bostrom, Autoliv Incorporated; Samantha Cockfield, TAC Victoria; Robert Hogan, Australia Dept. Infrastructure and Transport; Anja Kohsiek, Volkswagen; Anders Kullgren, Folksam Insurance; Nils Lubbe, Toyota Motor Corp.; Stuart Newstead, MUARC; Claus Pastor, BASt; Michiel van Ratingen, Euro NCAP; Jean-Louis Martin, IFSTTAR.

\section{REFERENCES}

Aga, M, Okada, A, Analysis of Vehicle Stability Control (VSC)'s Effectiveness from Accident Data, Enhanced Safety of Vehicles Conference, Paper \#541, Nagoya, Japan; 2003.

Bahouth G. Real World Crash evaluation of vehicle stability control (VSC) technology, 49th Annual Proceedings, Association for the Advancement of Automotive Medicine, September 12-14, 2005

Becker, H., Busch, S., Zobel, R., 2004. Methods for the evaluation of primary safety measures by means of accident research. In: 30th FISITA World Automotive Congress, Barcelona.

Cochran WG. The combination of estimates from different experiments. Biometrics 1954; 10: $101-129$

Dang, JN. Preliminary Results Analyzing the Effectiveness of Electronic Stability Control (ESC) Systems NHTSA Evaluation Note, DOT HS 809-790; September 2004. 34

Erke, A. Effects of electronic stability control (ESC) on accidents: A review of empirical evidence, Accident Analysis and Prevention 40 (2008) 167-173

Farmer, CM. Effect of electronic stability control on automobile crash risk, Traffic Injury Prevention, 5:2004; 317-325.

Farmer, C.M., Effects of electronic stability control: an update. Traffic Injury Prevention 7, 2006; 319-324.

Farmer C.M. Effects of Electronic Stability Control on Fatal Crash Risk, Report by the Insurance Institute for Highway Safety, Arlington VA, May 2010.

Giebel T., Meinecke MM., Gonter M. \& Widmann U. Current trends in vehicle active safety and driver assistance development, ATZAUTOTECHNOLOGY e-Magazine, 2008-09 Edition http://www.atzonline.com 
Green, P.E., Woodrooffe, J., 2006. The effectiveness of electronic stability control on motor vehicle crash prevention. University of Michigan Transport Research Institute, special report 12 .

Hosmer, D. W., Jr. and Lemeshow, S. (2000), Applied Logistic Regression, Second Edition, New York: John Wiley \& Sons

Høye, A. The effects of Electronic Stability Control (ESC) on crashes-an update, Accident Analysis and Prevention 43 (2011) 1148-1159.

Jens-Peter Kreiss J.P., Schüler, L. \& Langwieder, K. The effectiveness of primary safety features in passenger cars in Germany, Paper Number 05-0145, The Enhanced Safety of Vehicles Conference, Washington D.C. June 6-9, 2005

Keall MD, Newstead S. Induced Exposure Estimates of Rollover Risk for Different Types of Passenger Vehicles. Traffic Injury Prevention. 2009;10(1):30-36.

Keall MD, Newstead S. Selection of Comparison Crash Types for Quasi-Induced Exposure Risk Estimation. Traffic Injury Prevention. 2009;10(1):23-29.

Lie, A., Tingvall, C., Krafft,M., Kullgren, A., 2004. The effectiveness of ESP (electronic stability program) in reducing real life accidents. Traffic Injury Prevention 5, 37-41.

Lie, A., Tingvall, C., Krafft, M., Kullgren, A., The effectiveness of electronic stability control (ESC) in reducing real life crashes and injuries. Traffic Injury Prevention 7, (2006), 38-43.

Medical Dictionary (2013). The Medical Dictionary (2013). Meta-analysis - Definition of Meta-Analysis in the Medical Dictionary. http://medical-

dictionary.thefreedictionary.com/meta-analysis (downloaded 31/1/13)

Newstead, S. V., Watson, L. \& Cameron, M. H. (2010) Vehicle safety ratings estimated from police reported crash data: 2010 update. Australian and New Zealand crashes during 1987-2008_ Monash University Accident Research Centre, Report No. 297

Page Y. Cuny, S. Is electronic stability program effective on French roads? Accident Analysis and Prevention 38 (2006) 357-364

Resendes R. and Sill S. Integrated Vehicle-Based Safety Systems (IVBSS), Research and Innovative Technology Administration, U.S. Department of Transportation (US DOT), Washington DC www.its.dot.gov/ivbss/ (Updated August 3, 2012)

Sayer J, LeBlanc D, Bogard S, Funkhouser D, Bao S, Buonarosa ML. \& Blankespoor A. Integrated Vehicle-Based Safety Systems Field Operational Test Final Program, The University of Michigan Transportation Research Institute (UMTRI), Report DOT HS 811 482, U.S. Department of Transportation, Washington DC, June 2011.

Scully J. \& Newstead S. Preliminary evaluation of Electronic Stability Control effectiveness in Australasia, Report 271, Monash University Accident Research Centre, Melbourne, Australia, October 2007.

Scully J. \& Newstead S. Evaluation of electronic stability control effectiveness in Australasia, Accident Analysis and Prevention 40 (2008) 2050-2057

Sferco, R, Page, Y, LeCoz, J, Fay, P. Potential Effectiveness of Electronic Stability Programs (ESP) - What European Field Studies Tell Us, ESV, Paper \#2001-S2-0-327, Netherlands; 2001.

Thomas, P. (2006) 'Crash involvement risks of cars with electronic stability control systems in Great Britain, Int. J. Vehicle Safety, Vol. 1, No. 4, pp.267-281.

Tingvall, C, Krafft, M, Kullgren, A, Lie, A, The Effectiveness of ESP (Electronic Stability Programme) in Reducing Real Life Accidents, Enhanced Safety of Vehicles Conference, Paper \#261, Nagoya, Japan; 2003. 
Title: Evaluation of the Benefits of Vehicle Safety Technology: The MUNDS Study

\title{
Authors:
}

Brian Fildes, Monash University Accident Research Centre, Melbourne, Australia

Michael Keall, University of Otago, New Zealand

Pete Thomas, Transport Safety Research Centre, Loughborough University, UK

Kalle Parkkari, Finnish Motor Insurers Centre, VALT

Lucia Pennisi, Automobile Club of Italy, Rome, Italy

Claes Tingvall, Swedish Transport Administration, Borlänge, Sweden

\section{Contact Author:}

Brian N. Fildes, Monash University Accident Research Centre, Melbourne, Australia, Building 70, Monash University, Wellington Road, Clayton, 3800, Victoria, Australia, +61 39905 4369, email: brian.fildes@monash.edu.

\begin{abstract}
:
Real-world retrospective evaluation of the safety benefits of new integrated safety technologies is hampered by the lack of sufficient data to assess early reliable benefits. This MUNDS study set out to examine if a "prospective" case-control meta-analysis had the potential to provide more rapid and rigorous analyses of vehicle and infrastructure safety improvements. To examine the validity of the approach, an analysis of the effectiveness of ESC using a consistent analytic strategy across 6-European and Australasian databases was undertaken. It was hypothesized that the approach would be valid if the results of the MUNDS analysis were consistent with those published earlier (this would confirm the suitability of the MUNDS approach). The findings confirm the hypothesis and also found stronger and more robust findings across the range of crashtypes, road conditions, vehicle sizes and speed zones than previous. The study recommends that while a number of limitations were identified with the findings that need be addressed in future research, the MUNDS approach nevertheless should be adopted widely for the benefit of all vehicle occupants.
\end{abstract}

\section{Highlights:}

The study proposes a new and valid "prospective" method for conducting case-control meta-analyses of safety technologies to reduce the time taken to confirm their crash effectiveness.

\section{Key Words:}

Safety Technology, Data Analysis, Benefits, Crashes, Innovation 


\section{Introduction}

Advanced safety technologies are increasing rapidly in passenger and commercial vehicles as industry, government and the community currently focus on improved integrated safety systems (Giebel et al, 2008; Sayer et al, 2011). It is claimed that adopting an integrated safety approach has the capability of significantly reducing road trauma (Resendes and Sill, 2012). Unfortunately, there is only limited real-world evidence of their potential to reduce crashes or improved injury outcomes. It is critical to establish their likely crash benefits to help guide manufacturer, government and community judgments about which technologies should be pursued to encourage their widespread introduction and ensure maximum market penetration.

Real-world retrospective evaluation of safety benefits is hampered by the lack of sufficient data to obtain early reliable benefits of new innovative safety systems in vehicles and infrastructure. Individual crash databases are limited by the slow take-up rates of these new technologies as well as lower crash rates by owners of new safer vehicles. It took over 5-years for the benefits of Electronic Stability Control (ESC) braking systems to be initially reported, even in the USA where they have large, comprehensive databases of new vehicle populations and crashed vehicles (e.g., Lie, et al, 2004; Farmer 2004). New systems are commonly available on only a few car models and sometimes optional which increases the time needed to assess their benefits.

One way of potentially speeding up this process is to adopt a wider approach to collecting and analyzing crash data, rather than simply relying on one country's analysis from their limited crash numbers. In order to decrease the reporting time, it should be possible to increase the available relevant crash data by combining data from a number of countries and databases to enable mass data analyses to be conducted more quickly.

\subsubsection{The MUNDS Approach}

To test this hypothesis, a MUltiple National Database Study (MUNDS), was conducted using a case-control, meta-analysis, approach". Meta-analysis was first developed by the Scottish statistician, William Cochran during the 1950s who pioneered its use in medicine and health research (Cochran, 1954). Today, many Cochran reviews have been undertaken which are generally regarded as the highest standard in evidencebased health care. Many of these reviews are assembled from "retrospective" independent research case-control studies that require contributors to meet certain prerequisites for inclusion in the meta-analysis. For the most part, though, they come from independently published research, not necessarily initiated by those who assemble the overall findings.

The MUNDS study here differed in that the Chief Investigators actually prescribed what was to be analysed and the controlling factors from the data providers who agreed to participate. We call this a "prospective" meta-analysis approach. Aggregate analyses were undertaken in collaboration with a number of national police databases in Europe and Australasia and provided to the MUNDS team, ensuring a degree of consistent design across each analysis. While Erke (2008) and Høye (2011) have published the results of a "retrospective" meta-analysis of ESC technology, to the authors' knowledge, this is the first application of a "prospective" meta-analysis approach being used for the specific purpose of accelerating an evaluation in evaluating vehicle safety technology. 
To test the feasibility of the method, it was decided to select a safety technology that was now well established in terms of its effectiveness. As noted previously, one of the earlier technologies shown to reduce the number of crashes and injuries on the road was Electronic Stability Control or ESC. A number of studies have been undertaken on ESV which collectively show a marked reduction in the number of crashes (see Table 1).

\section{INSERT TABLE 1 ABOUT HERE}

Virtually all methods by which the effects of ESC on crashes have been investigated involve a comparison between the crash involvement of ESC-equipped vehicles and nonESC equipped vehicles (Høye, 2011). Ideally other vehicle and driver characteristics that might affect the risk estimated should be controlled for in some way. One common way of doing this, in conjunction with the fitment of statistical models with covariates, is to use a comparison group of crashes to represent exposure to risk. Such a comparison group of crashes should be those assumed not to be affected by ESC (or other attributes of ESC-equipped vehicles or their drivers), and commonly include rear-end collisions or other crashes not involving loss of control of the focus vehicle. Rear-end crashes, particularly those where the vehicle of interest is struck from the rear, provide quite a good measure of exposure to risk, although there is no perfect set of comparison crashes to provide this measure (Keall and Newstead, 2009).

\subsubsection{Study Objectives}

The MUNDS study set to compare its findings with relevant similar studies as a test of the feasibility of the new approach. The hypothesis to be tested is that the results of the MUNDS analysis are consistent with those published earlier (this would confirm the suitability of the MUNDS approach). In addition, other characteristics of the effectiveness of ESC in terms of crash and environmental features also generally concur.

\section{Method}

\subsubsection{Data}

Suitable national police data were available from Australia, Finland, Italy, New Zealand, Sweden and the UK for crash-involved light passenger vehicles manufactured in the year 2000 or later (see

Table ), excluding commercial vehicles (MPVs/vans, utility vehicles/pickup trucks). Only vehicles that could be definitely coded as having ESC or not were included in the analysis and those where ESC fitment was uncertain were excluded. Different countries have different thresholds for recording crashes, which can create difficulties in interpreting results when the data are combined. For this study, we chose the highest common threshold to define the scope of crashes studied: crashes in which an injury occurred to any road user involved in the crash. The one exception was Finland (see

Table 2), for whose data only included crashed vehicles where the driver was injured.

\section{INSERT TABLE 2 ABOUT HERE}

Note that there were differences between countries in terms of the proportions of the fleets identified with ESC. This was partially a function of the data bases in each country, partially a reflection of the fleets that were studied, and partially the restrictions placed on the data provided (for example, the Italian data only had late model vehicles). As the statistical models fitted included year of manufacture as a covariate and the outcome of 
interest was the ratio of crashes for given vehicle/road/country combinations, such intercountry differences did not adversely affect the estimates derived from the models fitted.

\subsubsection{Combining data sets}

A challenge for any analysis that derives single estimates of safety by combining different countries' crash data is data compatibility. This was examined by first meeting with each data provider to iron out any potential definitional issues. There were potential differences between countries in definitions of crash types, crash severity, speed limit thresholds, and crash conditions (including weather). Secondly, the inclusion criteria for crashes and vehicles needed to be consistent across countries, as did the data fields and specifications of categories. The specification of the data fields and categories are shown in

Table 3. Rear-end crashes are those where the vehicle in question was rear-ended by another vehicle and were used as controls in this analysis.

The model estimates averaged across countries were effectively weighted according to the number of observations (crashed vehicles) in each country. This meant that the data from smaller countries such as New Zealand and Finland, for example, had little influence on the overall estimates. The limitations of this approach are discussed below.

\section{INSERT TABLE 3 ABOUT HERE}

\subsubsection{Analysis}

Using a logistic regression technique, statistical models were fitted to the data to ensure that the estimates were adjusted for important factors that could confound estimates of ESC effectiveness. These included: vehicle ages, types and sizes; road conditions; driver age. Quasi-induced exposure methods (Keall and Newstead, 2009) were used to estimate the risk of crashes of particular types, where counts of rear-end crashes represented exposure to risk. Logistic models were fitted to an outcome variable $Y$ set as follows:

$Y=1$ (crashes excluding rear-ends)

$Y=0$ (rear-end crashes)

The odds of a non-rear-end crash using this data set are equivalent to the risk of nonrear-end crash involvement if the counts of rear-end crashes are considered to act as a measure of exposure to risk (ibid). These risk estimates could then be derived directly from the estimated coefficients generated by fitting the logistic models.

Explanatory variables included ESC (fitted or not fitted); Country; Year of Manufacture; Vehicle Type; Driver Age Category; Speed Zone; Road Condition; and any significant interactions between any two of these factors. The interaction terms and other covariates served to control for potentially confounding effects that could otherwise bias the estimates of ESC effectiveness, except in cases where variables interacted in a statistically significant manner with ESC fitment (which are shown as column headings in the following tables).

All models fitted well, with Hosmer-Lemeshow goodness-of-fit statistics (Hosmer and Lemeshow, 2000) that were not significant. There was some modest over-dispersion, symptomatic of some degree of clustering of the observations or heterogeneity within classes. This was allowed for by estimating an over-dispersion factor by using quasilikelihood estimation in the model fitting.

Given that those who own or manage crash databases were either unwilling or not able legally to provide individual case records to a single research facility, the MUNDS 
team structured a series of blank summary tables which were sent to each data provider for completion (see

Table 3). The tables of data were structured to provide the relevant data for the multivariate analysis. Completed tables and associated details were forwarded to the MUNDS statistician who then combined them as input for a series of overall analyses.

\section{Results}

\subsubsection{Single-Vehicle Crashes across Countries}

The results of relative risk of single vehicle crashes by country, road conditions, and speed limit with ESC are shown in Table 4. Relative risk was defined as that involving at least one injury for vehicles with ESC compared to vehicles without ESC, controlling for vehicle size, vehicle year of manufacture, and driver age group. The variables country, road conditions and speed limit were the only variables that had a statistically significant interaction with the ESC variable in the model, indicating that ESC effectiveness varied significantly across these aspects, but not across other variables once these interactions had been included.

\section{INSERT TABLE 4 ABOUT HERE}

The findings in Table 4 show some variability in the estimates of effectiveness between countries; with greatest effectiveness estimated from the Swedish data and least from the Finnish data. It should be noted, however, that there were large sampling errors, particularly for Finland, which were associated with relatively small sample sizes. This confirms the difficulty of finding robust results from a single country as well as crash differences between countries. In conditions where vehicles are most liable to lose control (wet/snow/ice), the estimates in Table 4 revealed greatest effectiveness for ESC, as expected. Similarly, ESC was found to be most effective in higher speed limit areas, related to the greater difficulty of maintaining control of vehicles at higher speeds.

\subsubsection{Single-Vehicle Crashes by Road, Speed and Vehicle Type}

In conditions where vehicles are most liable to lose control (wet/snow/ice), the estimates revealed greatest effectiveness for ESC as expected (Table 5). Similarly, ESC was found to be most effective in higher speed limit areas, probably related to greater difficulties by the driver in maintaining control of vehicles at high speed. Logically, the highest degree of effectiveness was estimated for higher speed limit roads when the roads are affected by rain/snow/ice (overall relative risk of 0.46 , with $95 \%$ CI 0.40 to 0.54 ).

\section{INSERT TABLE 5 ABOUT HERE}

Despite the lack of significance for the interaction between ESC fitment and vehicle size and type in this analysis, when this interaction was forced into the model, the resultant estimates enabled comparisons to be made between the current study and previous studies that included vehicle type. The largest difference was found for SUVs compared to cars (whether large or small) with a highly significant $66 \%$ reduction in crash risk for SUVs in higher speed limit roads in wet/snowy/icy road conditions.

Previous analyses of the effectiveness of ESC have found a differential effect by vehicle type, in particular greater effectiveness for SUVs in single vehicle crashes. The present analysis found that the variables speed limit area and weather conditions, together, were stronger variables in explaining the effectiveness of ESC than vehicle type, and variable type became statistically insignificant when the analysis was adjusted for speed limit and weather conditions. 


\subsubsection{Multi-Vehicle Crashes}

Statistical models were fitted to crashes involving multiple vehicles. Again, the reduction in risk of multi-vehicle crashes for vehicles with ESC compared to vehicles without ESC was estimated, controlling for vehicle size, vehicle year of manufacture, driver age group, as before. However, these models generally revealed smaller safety benefits for ESC in these crashes, which again is consistent with earlier analyses.

In this analysis, there was a $7 \%$ improvement on lower speed limit roads and $14 \%$ in higher speed zones. The average of these was a statistically significant $9 \%$ (95\% CI $4 \%$ $13 \%$ ) reduction in risk when weighted by crash numbers across the speed zones. However, as shown in Table 6, there was a significant interaction between speed zone with fitment of ESC in explaining crash risk.

\section{INSERT TABLE 6 ABOUT HERE}

\subsubsection{Comparative Findings}

A comparison of the overall findings from the MUNDS study with previous reported effectiveness studies is shown in Table 7. The degree of consistency is generally very high for all crashes (13\% c.f $16.7 \%$ and $22.1 \%$ by Lie et al, 2004 and 2006) although less than the figures of $45 \%$ reported by Becker et al (2003) in Germany and $44 \%$ (not significant) by Page and Cuny (2006) in France. Moreover, the findings of $35 \%$ for MUNDS effectiveness in single vehicle car crashes $52 \%$ for SUVs compared well with the range of earlier findings from $30.5 \%$ to $52.6 \%$ for cars and $49 \%$ to $68 \%$ for SUVs across the various Japanese, US and Australian figures. In addition, the MUNDS $9 \%$ reduction in multi-vehicle car crashes was reasonably consistent with similar reports by Bahouth (2005) and Farmer (2006) from Germany and the US.

\section{INSERT TABLE 7 ABOUT HERE}

\section{Discussion}

The MUNDS study set to compare its findings with relevant similar studies as a test of the validity of the new MUNDS prospective meta-analysis approach. The hypothesis tested was that the results of the MUNDS analysis are consistent with those published earlier. This was intended to confirm the feasibility of the MUNDS approach to elicit faster and more accurate estimates of real-world effectiveness than currently possible. Table 7 shows some results from previous studies with the comparative MUNDS study estimate in the final column. Although the best-fitting final model estimates from the MUNDS data have already been shown in Tables 4 and 5, models were refitted to generate the estimates in Table 7 by averaging across levels of disaggregation. For example, the estimate for all single vehicle crashes was produced by removing the interaction terms of ESC fitment with road conditions, speed limit and country from the model.

Because of the large amount of data accumulated, the estimates from the MUNDS study were produced from statistical models in which many potentially confounding variables were controlled for. Although comparisons between studies are difficult to make when the methods are different (e.g., the types of comparison crashes used), the MUNDS estimates turned out to be very close to the results of many of the earlier studies, particularly the Japanese, Australian and several of the American reports.

The benefits of the MUNDS approach can be seen in the often quite narrow confidence intervals, which enable relatively small safety benefits to be statistically significantly above zero. In the early days of evaluation of new technology, or when a 
single jurisdiction is studied, the statistical power to detect even quite substantial safety benefits is very limited (e.g., the $45 \%$ injury reduction that was not statistically significant in Page and Cuny, 2006).

\subsubsection{Characteristics of ESC Crashes}

An additional aspect of this study was to examine the relationships between ESC and other characteristics of the effectiveness of ESC (single-multiple vehicle crashes, road condition, speed limit, and vehicle type). Again, it was expected that these findings would be consistent with earlier findings as further indication of the validity of the MUNDS approach.

\subsubsection{Single- and Multi-Vehicle Crashes}

Previous studies have confirmed that the most obvious benefits of ESC relate to crashes of single-vehicles that lose control. Overall effectiveness benefits range from $30 \%$ to $40 \%$ reduction in crashes for passenger cars, to $49 \%$ up to $68 \%$ for Sport Utility Vehicles (SUVs). These values vary depending on the level of severity of the injury outcome, the road surface, and the study date and region.

In the MUNDS study, single-vehicle crash reductions among passenger cars varied from ( $30 \%$ to $55 \%$ ) and SUVs ( $42 \%$ to $66 \%$ ), again dependent on the speed zone of the crash, the road condition (dry or wet) and the size of the vehicle. In particular, larger cars had around a $5 \%$ additional benefit from ESC than did small cars, presumably because of the added benefit of vehicle mass as an injury mitigation measure. To our knowledge, no such finding has been previously reported. As in previous studies, the benefits of ESC in single-vehicle crashes are much greater in the wet and at higher crash speeds (higher speed zones).

Crash reductions for vehicle-to-vehicle collisions have been less impressive generally. In this study there was an $X \%$ reduction over all in multi-vehicle crashes which was not significant in itself, only when merged with speed zone ( $7 \%$ in low speed and $14 \%$ in high speed zones). It is likely that this is an artifact of the modeling process as rear-end crashes have been used in computing induced exposure, assuming they would not benefit from the technology (Dang 2004; Green \& Woodroofe, 2006; Scully and Newstead 2007). In the study by Bahouth (2005), he reported an $11.8 \%$ significant reduction in multi-vehicle frontal crashes using a similar induced exposure method to that used in this study. Dang (2006) reported a $19 \%$ crash reduction for multi-vehicle crashes which was not significant. Scully and Newstead also found a $14.2 \%$ significant reduction in multi-vehicle crashes using an induced exposure method. Both these study findings are consistent with the non-significant trend observed here.

Interestingly, in the study by Farmer (2010), he reported an even larger reduction for ESC of $20 \%$ overall in multi-vehicle crashes (a non-significant $16 \%$ for cars and $21 \%$ for SUVs). Farmer, however, used a different measure of exposure, namely per registered vehicle, to overcome the assumption that rear-end crashes are not influenced by ESC. While this did not appear to impact on the single-vehicle reductions, his findings might be a more realistic assessment of the benefit of ESC in all collisions.

\subsubsection{Road Condition}

The findings for road condition showed that in the conditions where vehicles are most likely to lose control (wet, snow and ice), the findings of the effectiveness of ESC for single vehicle crashes was significantly greater in the wet than on dry roads. Moreover, these findings were greater for crashes at lower speed limits than at higher ones (62\% at low and $23 \%$ high). 
In the study by Lie et al (2004), they reported a $43 \%$ improvement for ESC for wet roads and a $73 \%$ improvement for snow and icy roads, for all crashes of all speeds and all injury severities. In a later report, they claimed the benefits were $29 \%$ great for fatal and serious injury crashes with a substantial $100 \%$ plus added benefit among KSI crashes for wet, snow and icy roads. Farmer (2010) also found substantial benefits for ESC crashes on wet roads in the US comprising $55 \%$ to $63 \%$ for cars and SUVs in single vehicle crashes, and $73 \%$ to $38 \%$ for multi-vehicle collisions.

While these proportions are different across the three sets of data, not expected given the differences in crash types and injury severity, the trends are nevertheless consistent across these studies, confirming the ability of the MUNDS approach to simulate similar responses to those previously published.

\subsubsection{Speed Zone}

It has been claimed that the effects of ESC are likely to be greater at higher speeds where vehicle dynamics performance plays a greater part in the crash (Aga and Okada, 2003). Yet, very few of the previous studies attempted to examine the effects of ESC by the speed of the collision, given that national data does not include estimates of the collision speed. Newstead et al, (2010) used the speed limit in which a vehicle crashed as a proxy for low and high speed estimates of the crashes. As each of the databases used in the MUNDS study contained the speed zone in which the crash occurred, it was included as a factor in the meta-analysis.

The results here showed that the influence of ESC was up to twice as effective in preventing crashes in high speed zones as in low speed zones. These effects were consistent for dry and wet roads and for different vehicle types. Interestingly, too, the effects were also consistent for low and high speed zone single-vehicle and multi-vehicle crashes. While we were unable to compare these findings with other ESC effectiveness studies, nevertheless, they were consistent with claims made by Sferco et al (2001), Aga and Okada (2003), and Dang (2004) that inappropriate or excessive speed is frequently identified as a causation factor in both loss of control and other accidents.

\subsubsection{Vehicle Make and Model}

In the MUNDS analysis, ESC had a differential effect depending on vehicle size and type and speed zone. In all cases, the benefits were greater for SUVs over large and small passenger cars, and for large over small cars. The differences were consistent across the different road conditions and speed zones.

Previous studies on the effects of vehicle size are again consistent with these findings. Dang (2004), Green and Woodroofe (2006), Farmer (2006) and Scully and Newstead (2007) all reported significantly larger findings for SUVs over passenger cars. While the apparent slightly higher benefit for large over small cars shown earlier was not statistically significant as a main effect, the finding is consistent with these earlier results.

\subsubsection{The MUNDS Approach}

As noted earlier, this study set out to test the hypothesis that the results of the MUNDS effectiveness analysis (for Electronic Stability Control - ESC) would be consistent with those published earlier. We maintain that the results clearly confirm the validity of the MUNDS approach for estimating technology effectiveness. The findings for the various crash types, road conditions, vehicle size and, to a lesser extent, speed zones, were consistent with earlier findings. In addition, using a meta-analysis approach with 
strong control over the design of the various individual data analyses, resulted in significant findings, derived from a large sample, with smaller estimation errors.

The MUNDS analysis process aims to allow more rapid accurate assessment of the benefits of the effectiveness of new safety technologies. Using a much larger real-world database, the findings are superior in terms of scope of conditions, the numbers of observations, and the tight control exerted over the design and conduct of the various studies included. Many of the earlier studies varied considerably in terms of the study designs, control factors, variations in the data used, exposure processes adopted and various potential confounding factors.

In studies by Erke (2008) and Høye (2011), the authors conducted a meta-analysis of ESC using existing studies where it was not possible to exert the same level of strict control, hence subject to potential larger variance heterogeneity. Indeed, Erke (2008) noted large heterogeneity in their meta-analysis of existing studies. It is argued therefore that the MUNDS approach is indeed superior by the fact of its unique rigorous design and its ability to conduct these studies without having to wait until sufficient single studies have been published to before undertaking these analyses.

\subsubsection{Limitations}

We acknowledge however that the MUNDS study analysis was not without its limitations.

First, there was likely to be differences in the databases used in this study. While each contributor used national data, there are differences in the way and accuracy of data collection across the regions. In particular, the way each study assessed injury severity was likely to be different across databases. The Finnish database, for example, only included crashes that resulted in injuries to the driver, which is a source of some heterogeneity, but if we exclude the Finnish data in the analysis, the estimates are unaffected because of the small Finnish sample size. This of course is also a problem for "retrospective" analyses from different studies that also use different databases.

As the vehicle fleets differed across countries, these findings might not be representative of an overall fleet of vehicles. Given that it is region-specific, this is not necessarily a major problem for the analysis though. Indeed, it is probably more representative of Europe as a whole than a series of studies from individual countries. This would enable a more European- or international-wide analysis of effectiveness, making decisions about the need for widespread international fitment even stronger.

The use of speed zone as a proxy for crash severity is not without some criticism of the assumptions behind this. It assumes that higher speed zones are associated with higher speed crashes, which is plausible if used with large databases. Indeed, Newstead et al (2010) have used this technique in assessing real-world vehicle crashworthiness with some success. It would be useful, however, if this assumption was able to be tested more rigorously in future research.

\section{Conclusion}

As noted earlier, this study set out to test the hypothesis that the results of the MUNDS effectiveness analysis (for Electronic Stability Control - ESC) would be consistent with those published earlier. We contend that the results clearly confirm the validity of the MUNDS approach to estimating technology effectiveness. The values obtained for the effectiveness of ESC in single-vehicle crashes are within the range of values previous reported by several single evaluation studies using differing methodologies and exposure measures. The multi-vehicle findings, too, albeit of less significance, are also in general accord with other studies that used induced exposure metrics. In addition, the 
percentage reductions reported for the independent variables of road condition and vehicle size and type are further consistent with previous published findings.

The new methodology developed here using a prospective meta-analysis approach has the advantage of expediting the process of evaluating new vehicle safety technologies. In reality, it is the only feasible method to study real-world safety benefits when one data source is not sufficient. Drawing from a larger pool of crash data enhances the likelihood of demonstrating statistical significance with tighter confidence bounds. The MUNDS approach will be of potential benefit to vehicle manufacturers and suppliers, governments and consumer groups and advocates in prioritising future road safety improvements in active safety. While a number of limitations were identified with the findings that should be addressed in future research, nevertheless, the MUNDS approach needs to be adopted widely for the benefit of all road users.

\section{Acknowledgements}

The authors thank the project sponsors, the Swedish Transport Administration in Sweden and The Australian Government Department of Infrastructure and Transport in Australia for their support for this project. In addition, the support of the MUNDS Committee is also gratefully appreciated. Beyond those listed as authors) these people include Manuel Aviles, Spanish Ministry of Transport; Joerg Bakker, Daimler AG; Ola Bostrom, Autoliv Incorporated; Samantha Cockfield, TAC Victoria; Robert Hogan, Australia Dept. Infrastructure and Transport; Anja Kohsiek, Volkswagen; Anders Kullgren, Folksam Insurance; Nils Lubbe, Toyota Motor Corp.; Stuart Newstead, MUARC; Claus Pastor, BASt; Michiel van Ratingen, Euro NCAP; Jean-Louis Martin, IFSTTAR. 


\section{References}

Aga, M, Okada, A, Analysis of Vehicle Stability Control (VSC)'s Effectiveness from Accident Data, Enhanced Safety of Vehicles Conference, Paper \#541, Nagoya, Japan; 2003.

Bahouth G. Real World Crash evaluation of vehicle stability control (VSC) technology, 49th Annual Proceedings, Association for the Advancement of Automotive Medicine, September 12-14, 2005

Becker, H., Busch, S., Zobel, R., 2004. Methods for the evaluation of primary safety measures by means of accident research. In: 30th FISITA World Automotive Congress, Barcelona.

Cochran WG. The combination of estimates from different experiments. Biometrics 1954; 10: $101-129$

Dang, JN. Preliminary Results Analyzing the Effectiveness of Electronic Stability Control (ESC) Systems NHTSA Evaluation Note, DOT HS 809-790; September 2004. 34

Erke, A. Effects of electronic stability control (ESC) on accidents: A review of empirical evidence, Accident Analysis and Prevention 40 (2008) 167-173

Farmer, CM. Effect of electronic stability control on automobile crash risk, Traffic Injury Prevention, 5:2004; 317-325.

Farmer, C.M., Effects of electronic stability control: an update. Traffic Injury Prevention 7, 2006; 319-324.

Farmer C.M. Effects of Electronic Stability Control on Fatal Crash Risk, Report by the Insurance Institute for Highway Safety, Arlington VA, May 2010.

Giebel T., Meinecke MM., Gonter M. \& Widmann U. Current trends in vehicle active safety and driver assistance development, ATZAUTOTECHNOLOGY e-Magazine, 2008-09 Edition http://www.atzonline.com

Green, P.E., Woodrooffe, J., 2006. The effectiveness of electronic stability control on motor vehicle crash prevention. University of Michigan Transport Research Institute, special report 12 .

Hosmer, D. W., Jr. and Lemeshow, S. (2000), Applied Logistic Regression, Second Edition, New York: John Wiley \& Sons

Høye, A. The effects of Electronic Stability Control (ESC) on crashes-an update, Accident Analysis and Prevention 43 (2011) 1148-1159.

Jens-Peter Kreiss J.P., Schüler, L. \& Langwieder, K. The effectiveness of primary safety features in passenger cars in Germany, Paper Number 05-0145, The Enhanced Safety of Vehicles Conference, Washington D.C. June 6-9, 2005

Keall MD, Newstead S. Induced Exposure Estimates of Rollover Risk for Different Types of Passenger Vehicles. Traffic Injury Prevention. 2009;10(1):30-36.

Keall MD, Newstead S. Selection of Comparison Crash Types for Quasi-Induced Exposure Risk Estimation. Traffic Injury Prevention. 2009;10(1):23-29.

Lie, A., Tingvall, C., Krafft,M., Kullgren, A., 2004. The effectiveness of ESP (electronic stability program) in reducing real life accidents. Traffic Injury Prevention 5, 37-41.

Lie, A., Tingvall, C., Krafft, M., Kullgren, A., The effectiveness of electronic stability control (ESC) in reducing real life crashes and injuries. Traffic Injury Prevention 7, (2006), 38-43. 
Newstead, S. V., Watson, L. \& Cameron, M. H. (2010) Vehicle safety ratings estimated from police reported crash data: 2010 update. Australian and New Zealand crashes during 1987-2008 Monash University Accident Research Centre, Report No. 297

Page Y. Cuny, S. Is electronic stability program effective on French roads? Accident Analysis and Prevention 38 (2006) 357-364

Resendes R. and Sill S. Integrated Vehicle-Based Safety Systems (IVBSS), Research and Innovative Technology Administration, U.S. Department of Transportation (US DOT), Washington DC www.its.dot.gov/ivbss/ (Updated August 3, 2012)

Sayer J, LeBlanc D, Bogard S, Funkhouser D, Bao S, Buonarosa ML. \& Blankespoor A. Integrated Vehicle-Based Safety Systems Field Operational Test Final Program, The University of Michigan Transportation Research Institute (UMTRI), Report DOT HS 811 482, U.S. Department of Transportation, Washington DC, June 2011.

Scully J. \& Newstead S. Preliminary evaluation of Electronic Stability Control effectiveness in Australasia, Report 271, Monash University Accident Research Centre, Melbourne, Australia, October 2007.

Scully J. \& Newstead S. Evaluation of electronic stability control effectiveness in Australasia, Accident Analysis and Prevention 40 (2008) 2050-2057

Sferco, R, Page, Y, LeCoz, J, Fay, P. Potential Effectiveness of Electronic Stability Programs (ESP) - What European Field Studies Tell Us, ESV, Paper \#2001-S2-0-327, Netherlands; 2001.

Thomas, P. (2006) 'Crash involvement risks of cars with electronic stability control systems in Great Britain, Int. J. Vehicle Safety, Vol. 1, No. 4, pp.267-281.

Tingvall, C, Krafft, M, Kullgren, A, Lie, A, The Effectiveness of ESP (Electronic Stability Programme) in Reducing Real Life Accidents, Enhanced Safety of Vehicles Conference, Paper \#261, Nagoya, Japan; 2003. 
Table 1: Summary of Retrospective Studies of ESC Effectiveness (from Scully and Newstead, 2007)

\begin{tabular}{|c|c|c|c|c|}
\hline Author \& Year & Jurisdiction & Crash type & $\begin{array}{l}\text { Exposure } \\
\text { Measure }\end{array}$ & $\begin{array}{l}\text { Crash } \\
\text { reduction }\end{array}$ \\
\hline Becker et al, 2003 & Germany & Skidding accidents & & $45 \%$ \\
\hline Aga \& Okada, 2003 & Japan & $\begin{array}{l}\text { All single vehicle crashes } \\
\text { Severe single vehicle crashes } \\
\text { Head-on crashes } \\
\text { Severe head-on crashes }\end{array}$ & & $\begin{array}{l}35 \% \\
50 \% \\
30 \% \\
40 \%\end{array}$ \\
\hline Lie et al, 2004 & Sweden & $\begin{array}{l}\text { All crashes } \\
\text { All crashes - wet roads } \\
\text { All crashes - snow \& ice }\end{array}$ & $\begin{array}{l}\text { induced } \\
\text { exposure }\end{array}$ & $\begin{array}{l}22.1 \% \\
31.5 \% \\
38.2 \%\end{array}$ \\
\hline Farmer, 2004 & USA & $\begin{array}{l}\text { All single vehicle crashes } \\
\text { Fatal single vehicle crashes }\end{array}$ & $\begin{array}{l}\text { vehicle } \\
\text { registration }\end{array}$ & $\begin{array}{l}41.0 \% \\
56.0 \%\end{array}$ \\
\hline Dang, 2004 & USA & $\begin{array}{l}\text { All single car crashes } \\
\text { All single SUV crashes } \\
\text { Fatal single car crashes } \\
\text { Fatal single SUV crases }\end{array}$ & $\begin{array}{l}\text { induced } \\
\text { exposure }\end{array}$ & $\begin{array}{l}35 \% \\
67 \% \\
30 \% \\
63 \%\end{array}$ \\
\hline Kriess et al, 2005 & Germany & $\begin{array}{l}\text { All ESC sensitive crashes } \\
\text { Fatal ESC sensitive crashes }\end{array}$ & $\begin{array}{l}\text { induced } \\
\text { exposure }\end{array}$ & $\begin{array}{l}32.4 \% \\
55.5 \%\end{array}$ \\
\hline Bahouth, 2005 & USA & $\begin{array}{l}\text { Multi-vehicle crashes } \\
\text { Single-vehicle crashes }\end{array}$ & $\begin{array}{l}\text { induced } \\
\text { exposure }\end{array}$ & $\begin{array}{l}11.2 \% \\
52.6 \%\end{array}$ \\
\hline Page \& Cuny, 2006 & France & All crashes & $\begin{array}{l}\text { induced } \\
\text { exposure }\end{array}$ & $\begin{array}{c}44 \% \\
\text { (not sig) }\end{array}$ \\
\hline $\begin{array}{l}\text { Green \& Woodroofe, } \\
2006\end{array}$ & USA & $\begin{array}{l}\text { Single car crash - dry road } \\
\text { Single SUV crash - dry road } \\
\text { Rollover car crash - dry road } \\
\text { Rollover SUV crash - dry road } \\
\text { Run-off-road car crash } \\
\text { Run-off-road SUV crash }\end{array}$ & $\begin{array}{l}\text { induced } \\
\text { exposure }\end{array}$ & $\begin{array}{l}30.5 \% \\
49.5 \% \\
39.7 \% \\
72.9 \% \\
54.5 \% \\
70.3 \%\end{array}$ \\
\hline Lie et al, 2006 & Sweden & $\begin{array}{l}\text { All injury crashes (no rear-end) } \\
\text { All KSI crashes } \\
\text { Lost control KSI crash - wet } \\
\text { Lost control KSI crash - ice/snow }\end{array}$ & $\begin{array}{l}\text { induced } \\
\text { exposure }\end{array}$ & $\begin{array}{l}16.7 \% \\
21.6 \% \\
56.2 \% \\
49.2 \%\end{array}$ \\
\hline Farmer, 2006 & USA & $\begin{array}{l}\text { All single car crashes } \\
\text { All single SUV crashes } \\
\text { Fatal single car crashes } \\
\text { Fatal single SUV crashes } \\
\text { Multi-vehicle car crashes } \\
\text { Multi-vehicle SUV crashes }\end{array}$ & $\begin{array}{l}\text { vehicle } \\
\text { registration }\end{array}$ & $\begin{array}{c}33 \% \\
49 \% \\
53 \% \\
59 \% \\
25 \% \\
32-37 \%\end{array}$ \\
\hline Scully \& Newstead, 2007 & Australia & $\begin{array}{l}\text { All vehicles (driver injured) } \\
\text { All single car crashes } \\
\text { All single SUV crashes }\end{array}$ & $\begin{array}{l}\text { induced } \\
\text { exposure }\end{array}$ & $\begin{array}{l}32 \% \\
27 \% \\
68 \%\end{array}$ \\
\hline Thomas, 2006 & UK & $\begin{array}{l}\text { All crashes (driver injured) } \\
\text { Wet roads } \\
\text { lcy roads } \\
\text { Small cars }\end{array}$ & $\begin{array}{l}\text { induced } \\
\text { exposure }\end{array}$ & $\begin{array}{l}3 \% \\
34 \% \\
53 \% \\
47 \%\end{array}$ \\
\hline
\end{tabular}


Table 2: Number of vehicles manufactured from 2000 to 2008 involved in an injury crash that were included in the analysis (excluding those vehicles where ESC fitment was unknown)

\begin{tabular}{|c|c|c|c|c|c|c|c|}
\hline $\begin{array}{l}\text { ESC } \\
\text { fitted? }\end{array}$ & Australia* & Finland** & Italy $^{+}$ & $\begin{array}{c}\text { New } \\
\text { Zealand }\end{array}$ & Sweden & UK & Total \\
\hline No & 24,324 & 3,646 & 5,034 & 2,828 & 12,859 & 23,942 & 72,633 \\
\hline Yes & 1,247 & 343 & 14,614 & 194 & 4,880 & 7,172 & 28,450 \\
\hline Total & 25,571 & 3,989 & 19,648 & 3,022 & 17,739 & 31,114 & 101,083 \\
\hline Years & $2001-5$ & $2000-8$ & 2008 & 2001-5 & $2003-10^{++}$ & $2002-5$ & \\
\hline
\end{tabular}


Table 3: Data fields and categories used in international analysis of ESC effectiveness

\begin{tabular}{ccccccccc}
\hline $\begin{array}{c}\text { ESC } \\
\text { fitted? }\end{array}$ & $\begin{array}{c}\text { Year of } \\
\text { M'facture }\end{array}$ & $\begin{array}{c}\text { Vehicle } \\
\text { size }\end{array}$ & $\begin{array}{c}\text { Driver } \\
\text { age }\end{array}$ & $\begin{array}{c}\text { Driver } \\
\text { injury }\end{array}$ & $\begin{array}{c}\text { Crash } \\
\text { Type }\end{array}$ & $\begin{array}{c}\text { Single } \\
\text { Vehicle }\end{array}$ & $\begin{array}{c}\text { Speed } \\
\text { Zone }\end{array}$ & $\begin{array}{c}\text { Road } \\
\text { Cond'n }\end{array}$ \\
\hline Yes/No & year & Large & $<25$ & Fatal & Head-on & Yes $/$ no & $<75 \mathrm{~km} / \mathrm{h}$ & Dry \\
& & small & $25-29$ & Serious & Rollover & & $>75 \mathrm{~km} / \mathrm{h}$ & Wey \\
& & SUV & $30-39$ & Minor & Rear-end & & & Snow \\
& & & $40-49$ & None & other & & & Ice \\
& & & & & & & & \\
\hline
\end{tabular}


Table 4: By country, road conditions, and speed limit area: reduction in risk of single vehicle crashes that involved at least one injury for vehicles with ESC compared to vehicles without ESC, controlling for vehicle size, vehicle year of manufacture, driver age group

\begin{tabular}{|c|c|c|c|c|}
\hline & \multicolumn{4}{|c|}{ Road conditions } \\
\hline & Wet/Snow/Ice & Wet/Snow/Ice & Dry & Dry \\
\hline Country & $<75 \mathrm{KMH}$ & $\geq 75 \mathrm{KMH}$ & $<75 \mathrm{KMH}$ & $\geq 75 \mathrm{KMH}$ \\
\hline Australia & $12 \%(-24 \%, 37 \%)$ & $43 \%(20 \%, 60 \%)$ & $-8 \%(-48 \%, 21 \%)$ & $31 \%(3 \%, 51 \%)$ \\
\hline Finland* & $2 \%(-49 \%, 36 \%)$ & $38 \%(5 \%, 59 \%)$ & $-19 \%(-80 \%, 21 \%)$ & $24 \%(-15 \%, 49 \%)$ \\
\hline Italy & $38 \%(25 \%, 49 \%)$ & $61 \%(51 \%, 68 \%)$ & $25 \%(13 \%, 35 \%)$ & $52 \%(42 \%, 60 \%)$ \\
\hline New Zealand & $22 \%(-61 \%, 63 \%)$ & $50 \%(-3 \%, 76 \%)$ & $5 \%(-96 \%, 54 \%)$ & $39 \%(-26 \%, 71 \%)$ \\
\hline Sweden & $49 \%(38 \%, 58 \%)$ & $67 \%(60 \%, 73 \%)$ & $37 \%(26 \%, 48 \%)$ & $60 \%(51 \%, 67 \%)$ \\
\hline UK & $7 \%(-14 \%, 24 \%)$ & $40 \%(28 \%, 50 \%)$ & $-14 \%(-38 \%, 6 \%)$ & $27 \%(13 \%, 39 \%)$ \\
\hline Average $(95 \% \mathrm{Cl})$ & $34 \%(23 \%, 43 \%)$ & $54 \%(46 \%, 60 \%)$ & $21 \%$ (11\%, 29\%) & $44 \%(36 \%, 51 \%)$ \\
\hline
\end{tabular}

*Figures in BOLD were those found to be statistically significant (95\% confidence) 
Table 5: By vehicle type, speed zone, and road conditions

\begin{tabular}{lccc}
\hline Vehicle & Speed zone & Road conditions & Reductions \\
\hline Small car & $<75 \mathrm{~km} / \mathrm{h}$ & Wet/Snow/Ice & $31 \%(18 \%-41 \%)$ \\
Small car & $<75 \mathrm{~km} / \mathrm{h}$ & Dry & $17 \%(8 \%-27 \%)$ \\
Small car & $\geq 75 \mathrm{~km} / \mathrm{h}+$ & Wet/Snow/Ice & $51 \%(41 \%-59 \%)$ \\
Small car & $\geq 75 \mathrm{~km} / \mathrm{h}+$ & Dry & $41 \%(31 \%-49 \%)$ \\
\hline Large car & $<75 \mathrm{~km} / \mathrm{h}$ & Wet/Snow $/ \mathrm{Ice}$ & $37 \%(24 \%-48 \%)$ \\
Large car & $<75 \mathrm{~km} / \mathrm{h}$ & Dry & $25 \%(11 \%-36 \%)$ \\
Large car & $\geq 75 \mathrm{~km} / \mathrm{h}+$ & Wet $/$ Snow $/ \mathrm{Ice}$ & $55 \%(46 \%-63 \%)$ \\
Large car & $\geq 75 \mathrm{~km} / \mathrm{h}+$ & Dry & $46 \%(36 \%-55 \%)$ \\
\hline sUV & $<75 \mathrm{~km} / \mathrm{h}$ & Wet $/$ Snow $/ \mathrm{Ice}$ & $52 \%(28 \%-67 \%)$ \\
sUV & $<75 \mathrm{~km} / \mathrm{h}$ & Dry & $42 \%(16 \%-60 \%)$ \\
SUV & $\geq 75 \mathrm{~km} / \mathrm{h}+$ & Wet/Snow/Ice & $66 \%(49 \%-77 \%)$ \\
sUV & $\geq 75 \mathrm{~km} / \mathrm{h}+$ & Dry & $59 \%(40 \%-72 \%)$ \\
\hline
\end{tabular}


Table 6: Reduction in risk of multi-vehicle injury crashes by country and speed limit area (statistically significant changes are bolded; negative values are estimated increases)

\begin{tabular}{|c|c|c|}
\hline \multirow[b]{2}{*}{ Country } & \multicolumn{2}{|c|}{ Speed limit of crash site } \\
\hline & $<75 \mathrm{KMH}$ & $\geq 75 \mathrm{KMH}$ \\
\hline Australia & $-7 \%(-24 \%, 9 \%)$ & $6 \%(-12 \%, 21 \%)$ \\
\hline Finland* & $-14 \%(-72 \%, 25 \%)$ & $0 \%(-53 \%, 35 \%)$ \\
\hline Italy & $9 \%(-1 \%, 18 \%)$ & $20 \%(9 \%, 30 \%)$ \\
\hline New Zealand & $-11 \%(-70 \%, 28 \%)$ & $3 \%(-50 \%, 37 \%)$ \\
\hline Sweden & $20 \%(12 \%, 27 \%)$ & $29 \%(19 \%, 38 \%)$ \\
\hline UK & $-3 \%(-13 \%, 5 \%)$ & $9 \%(0 \%, 17 \%)$ \\
\hline Average $(95 \% \mathrm{Cl})$ & $7 \%(1 \%, 12 \%)$ & $14 \%(6 \%, 21 \%)$ \\
\hline
\end{tabular}

*Finland data consists solely of crashes where the driver was injured 
Table 7: Comparison between MUNDS study of ESC and other studies

\begin{tabular}{|c|c|c|c|c|}
\hline Author \& Year & Jurisdiction & Crash type & $\begin{array}{l}\text { Crash } \\
\text { reduction }\end{array}$ & $\begin{array}{l}\text { MUNDS } \\
\text { estimates }\end{array}$ \\
\hline Becker et al, 2003 & Germany & Skidding accidents & $45 \%$ & $13 \%(9 \%-17 \%)$ \\
\hline Aga \& Okada, 2003 & Japan & All single vehicle crashes & $35 \%$ & $35 \%(29 \%-40 \%)$ \\
\hline Lie et al, 2004 & Sweden & $\begin{array}{l}\text { All crashes } \\
\text { All crashes - wet roads } \\
\text { All crashes - snow \& ice }\end{array}$ & $\begin{array}{l}22.1 \% \\
31.5 \% \\
38.2 \%\end{array}$ & $\begin{array}{l}13 \%(9 \%-17 \%) \\
15 \%(8 \%-21 \%)^{\star}\end{array}$ \\
\hline Farmer, 2004 & USA & All single vehicle crashes & $41.0 \%$ & $35 \%(29 \%-40 \%)$ \\
\hline Dang, 2004 & USA & $\begin{array}{l}\text { All single car crashes } \\
\text { All single SUV crashes }\end{array}$ & $\begin{array}{l}35 \% \\
67 \%\end{array}$ & $\begin{array}{l}35 \%(29 \%-40 \%) \\
52 \%(30 \%-67 \%)\end{array}$ \\
\hline Bahouth, 2005 & USA & $\begin{array}{l}\text { Multi-vehicle crashes } \\
\text { Single-vehicle crashes }\end{array}$ & $\begin{array}{l}11.2 \% \\
52.6 \%\end{array}$ & $\begin{array}{c}9 \%(4 \%-13 \%) \\
35 \%(29 \%-40 \%)\end{array}$ \\
\hline Page \& Cuny, 2006 & France & All crashes & $44 \%$ (not sig) & $13 \%(9 \%-17 \%)$ \\
\hline $\begin{array}{l}\text { Green \& } \\
\text { Woodroofe, } 2006\end{array}$ & USA & $\begin{array}{l}\text { Single car crash - dry road } \\
\text { Single SUV crash - dry road }\end{array}$ & $\begin{array}{l}30.5 \% \\
49.5 \%\end{array}$ & $\begin{array}{l}30 \%(22 \%-36 \%) \\
49 \%(26 \%-65 \%)\end{array}$ \\
\hline Lie et al, 2006 & Sweden & All injury crashes (no rear-end) & $16.7 \%$ & $13 \%(9 \%-17 \%)$ \\
\hline Farmer, 2006 & USA & $\begin{array}{l}\text { All single car crashes } \\
\text { All single SUV crashes } \\
\text { Multi-vehicle car crashes } \\
\text { Multi-vehicle SUV crashes }\end{array}$ & $\begin{array}{c}33 \% \\
49 \% \\
5 \% \\
32-37 \%\end{array}$ & $\begin{array}{c}35 \%(29 \%-40 \%) \\
52 \%(30 \%-67 \%) \\
9 \%(5 \%-13 \%) \\
6 \%(-17 \%-25 \%)\end{array}$ \\
\hline $\begin{array}{l}\text { Scully \& Newstead, } \\
2007\end{array}$ & Australia & $\begin{array}{l}\text { All single car crashes } \\
\text { All single SUV crashes }\end{array}$ & $\begin{array}{l}27 \% \\
68 \%\end{array}$ & $\begin{array}{l}35 \%(29 \%-40 \%) \\
52 \%(30 \%-67 \%)\end{array}$ \\
\hline Thomas, 2006 & UK & $\begin{array}{l}\text { Wet roads all crashes? } \\
\text { Icy roads all crashes? } \\
\text { Small cars all crashes? }\end{array}$ & $\begin{array}{l}34 \% \\
53 \% \\
47 \%\end{array}$ & $\begin{array}{c}15 \%(8 \%-21 \%)^{*} \\
n / a \\
10 \%(4 \%-15 \%)\end{array}$ \\
\hline
\end{tabular}

*the MUNDs estimates combine wet, snow and ice 